\title{
Thermorheological Characterization of Healthier Reduced-Fat Cocoa Butter Formulated by Substitution with a Hydroxypropyl Methylcellulose (HPMC)-Based Oleogel
}

\author{
María Dolores Alvarez ${ }^{1, *(\mathbb{D})}$, Susana Cofrades ${ }^{1}$, María Espert ${ }^{2}$, Ana Salvador ${ }^{2}$ (D) and Teresa Sanz ${ }^{2}$ \\ 1 Instituto de Ciencia y Tecnología de Alimentos y Nutrición (ICTAN-CSIC), 28040 Madrid, Spain; \\ scofrades@ictan.csic.es \\ 2 Instituto de Agroquímica y Tecnología de Alimentos (IATA-CSIC), 46980 Paterna, Spain; \\ mespert@iata.csic.es (M.E.); asalvador@iata.csic.es (A.S.); tesanz@iata.csic.es (T.S.) \\ * Correspondence: mayoyes@ictan.csic.es
}

check for updates

Citation: Alvarez, M.D.; Cofrades, S. Espert, M.; Salvador, A.; Sanz, T. Thermorheological Characterization of Healthier Reduced-Fat Cocoa Butter Formulated by Substitution with a Hydroxypropyl Methylcellulose (HPMC)-Based Oleogel. Foods 2021, 10, 793. https:// doi.org/10.3390/foods10040793

Academic Editor: Domenico Gabriele

Received: 12 March 2021

Accepted: 6 April 2021

Published: 7 April 2021

Publisher's Note: MDPI stays neutral with regard to jurisdictional claims in published maps and institutional affiliations.

Copyright: (c) 2021 by the authors. Licensee MDPI, Basel, Switzerland. This article is an open access article distributed under the terms and conditions of the Creative Commons Attribution (CC BY) license (https:// creativecommons.org/licenses/by/ $4.0 /)$

\begin{abstract}
Cocoa butter (CB) is a main ingredient in pastry due to the unique functional properties of its fat, which is high in saturated fatty acids (SFAs). However, excessive consumption of SFAs is associated with the occurrence of several chronic diseases. This study researched the partial or total replacement of CB by an oleogel (OG) formulated with a healthier lipid profile, for mixed systems that would allow a partial substitution of $\mathrm{CB}$ in confectionery products. The "emulsion-templated approach" was used to develop a sunflower oil-HPMC-based OG. Different CB:OG ratios were formulated increasing the percentage replacement of CB by OG from 50 to $100 \%$. Rheological and textural properties were determined and compared with a CB control at 20 and $10{ }^{\circ} \mathrm{C}$. Oil-binding capacity was also analyzed. The systems showed a solid-like behavior, with higher elastic than viscous modulus, which increased with $\mathrm{CB}$ concentration. Compared with $20^{\circ} \mathrm{C}$, at $10^{\circ} \mathrm{C}$ there was an increase in connectivity, viscoelasticity, and consistency of the systems, in response to a more complete CB crystallization. The replaced systems also presented a better lipid profile than CB. This evidence suggests that formulated CB:OG system at 50:50 ratio could become useful as a CB equivalent in chocolate products.
\end{abstract}

Keywords: cocoa butter; hydroxypropyl methylcellulose; emulsion-templated approach; edible oleogel; thermorheological properties; fatty acids profile

\section{Introduction}

Recently, consumer awareness of the relationship between diet and health has increased reduction of saturated fatty acids SFAs and elimination of trans-fatty acids (FAs) present in solid fats by substituting them with essential and polyunsaturated fatty acids (PUFAs), to diminish the risk of cardiovascular disease, obesity and diabetes [1-3], which converges with the World Health Organization (WHO) recommendations [4]. However, saturated fats are responsible for many high-quality attributes in foodstuffs, such as aroma, stability, taste and texture, and therefore, both fat reduction and fat replacement are not easy tasks for food manufacturers [5,6]. Substituting saturated fats (solid at room temperature) with liquid oils alters the behavior of fat and of products made with fat replacers, especially fat crystallization and specific melting profile, which affect sensory attributes such as spreadability, mouthfeel, snap of chocolate, hardness, palatability, etc. [6,7].

Currently, manufacturers and researchers are focusing on different technological options to structure liquid oils for their use as saturated fat replacers, hence mimicking fat functionality in food products without changing the nutritional profile of liquid oils $[1,8]$. In this context, organogelification converts liquid oils into soft matter structures with solidlipid functionality in line with that of saturated fats [1,2,9]. Oleogels are structured oils prepared by oleogelation of liquid oils using oleogelators, which have features (rheological 
properties, viscoelasticity, plasticity, consistency, etc.) of solid fats, but contain a low quantity of SFAs $[10,11]$. Oleogelators can be classified as polymeric and low-molecular weight $[2,12]$. Among them, current research focus is the use of hydrocolloids as oil structuring agents through indirect methods [13-17].

The emulsion-templated approach for oil structuring is described as an indirect method to obtain oleogels by first creating a water continuous emulsion, followed by removing water and further shearing the dried emulsion [18-20]. These oleogels can be considered to be fat analogs as they contain a high concentration (above $97 \mathrm{wt} . \%$ ) of edible oil [11]. However, oil droplets in concentrated emulsions tend to coalesce during the drying process [17]. To avoid coalescence of oil droplets, the creation of a strengthened emulsion interface by using thickener agents has shown to be effective in combinations such as regenerated cellulose and carboxymethyl cellulose [21] and methylcellulose/hydroxypropyl methylcellulose and xanthan gum [13-16]. Therefore, the research of single or combined hydrocolloids as oil-gelling agents and new sustainable indirect methods as the emulsiontemplated approach, would greatly contribute to increasing the field of application of oleogels and the generalization of their use in food technology.

Regarding the production of oleogels, there is limited literature concerning the use of hydroxypropyl methylcellulose (HPMC) [14]. The authors just cited used the emulsiontemplated method to prepare oleogels with soybean oil and a wide range of HPMC concentrations, observing that the mechanical strength increased with HPMC concentration. Recently, Espert et al. [18] have pointed out the suitability of HPMC emulsions without additional thickeners to obtain oleogels. HPMC use has also proven to be a good strategy to diminish the effective caloric content of foods, and to control fat digestion or satiety $[5,22,23]$.

Genuine cocoa butter (CB) is mainly used in pastry and confectionery to make both dark and white chocolate products due to its unique triacylglycerol (TAG) composition that provides the exclusive physical and sensory characteristics of this ingredient [24,25]. In turn, $\mathrm{CB}$ is the most expensive ingredient among chocolate products and, to minimize costs, cocoa butter equivalents, substitutes or improvers are typically used as CB replacers $[24,26,27]$. These alternative fat and oil sources are obtained by using chemical or enzymatic methods, to resemble the TAG of CB [28,29]. However, although CB equivalents are used to develop low-priced and appropriate alternatives to $\mathrm{CB}$ [25], they do not meet actual consumer demand for low fat foodstuffs with a healthier lipid profile, while retaining their technological and sensory characteristics.

The suitability of a HPMC-based OG obtained by the emulsion-templated approach for partial substitution of $\mathrm{CB}$ in confectionery products, improving their nutritional quality by reducing saturated fat content, has not been investigated. In this study, the objective was to investigate the effect of percentage replacement of $\mathrm{CB}$ by an OG enhanced with a healthy oil stabilized by HPMC on the thermorheological behavior and the consistency of the different CB:OG systems, using a combination of small amplitude oscillation sweeps (SAOS) and large deformation penetration texture tests. In addition, the oil-binding capacity $(\mathrm{OBC})$ and the fatty acid (FA) composition of the CB:OG systems were also analyzed. It is expected that the obtained OG may partially substitute CB in chocolate products reducing their cost, but with the advantage of reducing intake of SFAs and that is compatible with the particular physical and sensory properties provided by CB.

\section{Materials and Methods}

\subsection{Materials}

The emulsion and the OG were prepared with high oleic refined sunflower oil (HORSO), drinking water, and a type of HPMC. Sunflower oil "Capicua" was purchased from Coreysa (Sevilla, Spain). HPMC (METHOCEL ${ }^{\mathrm{TM}}$ F4M Food Grade) was employed as organogelator and provided by The Dow Chemical Company (Bomlitz, Germany). This HPMC has chemical substitution of $29 \mathrm{~g} / 100 \mathrm{~g}$ methoxyl and $6.8 \mathrm{~g} / 100 \mathrm{~g}$ hydroxypropyl, its viscosity is of $4000 \mathrm{mPa} s$ at $2 \%$ aqueous solution and $20^{\circ} \mathrm{C}$, its average molecular weight $\left(M_{n}\right)$ is of 86,000 as measured by The Dow Chemical Company. In addition, the 
polydispersity of this linear polymer is approximately 3.0. Barry white cacao pearls were employed in the preparation of the CB:OG systems as the CB source, and were supplied by Barry Callebaut Manufacturing Iberica S.A.U. (Barcelona, Spain).

\subsection{Emulsion and Oleogel (OG) Preparation}

The oil-in-water emulsion stabilized by HPMC was composed of sunflower oil $(47 \% w / w, 94 \mathrm{~g}), \operatorname{HPMC}(1 \% w / w, 2 \mathrm{~g})$ and drinking water $(52 \% w / w, 104 \mathrm{~g})$ for a total final mass of $200 \mathrm{~g}$. The proportions were chosen in accordance with the results of a previous study where two oil concentrations (47 and 60\%) and three HPMC concentrations $(0.5,1$ and $2 \%$ ) were compared [18]. HPMC was first dispersed in the oil using a Bunsen (AGV-8) rod stirrer at low speed ( $300 \mathrm{rpm}$ ) for $5 \mathrm{~min}$. Then, the mixture was hydrated by gradually adding the water at $10^{\circ} \mathrm{C}$ for $30 \mathrm{~s}$. The $200 \mathrm{~g}$ mixture was then homogenized using a high-energy dispersing unit IKA T25 basic (Ultra-Turrax) with the dispersion tool S18N-19G, at $6500 \mathrm{rpm}$ for $15 \mathrm{~s}$, and subsequently at $17,500 \mathrm{rpm}$ for $60 \mathrm{~s}$. The resulting emulsion was then immediately poured into plastic trays (155 mm length $\times 140 \mathrm{~mm}$ width $\times 30 \mathrm{~mm}$ depth) forming a thin layer.

The drying of the emulsion was carried out using forced convection air in a climate chamber (KBF240, Binder Iberica, Barcelona, Spain) at $60^{\circ} \mathrm{C}$ for $30 \mathrm{~h}$, obtaining sheets of about $10 \mathrm{~mm}$ thickness. The complete removal of water to $0.0-0.5 \%$ moisture content was confirmed by the weight difference between the emulsion and dried product. The total elimination of water from the emulsion resulted in the development of solid-like structures formed by HPMC, with a high proportion of embedded oil.

Following, the OG was prepared by uniformly shearing the dried product in accordance with Patel et al. [11] and Espert et al. [18], using a conventional A320R1 mincer (Moulinex, Gruope Seb Ibérica, Barcelona, Spain) and performing 5 cycles of $3 \mathrm{~s}$ of duration each. Then, the OG smooth mixture obtained was molded into plastic buckets ( 12 $\mathrm{g}$ of product at each bucket $(20 \times 30 \mathrm{~mm}))$ to attain a homogeneous oil-sorbed material, and finally cooled and stored at refrigeration temperature $\left(4^{\circ} \mathrm{C}\right)$ for $24 \mathrm{~h}$ until further analysis.

\subsection{CB:OG Systems Preparation}

Five different CB:OG systems were prepared by partially $(50,60,70$ and $80 \%)$ and totally (100\%) replacing CB by the OG (CB:OG, 50:50, 40:60, 30:70, 20:80 and 0:100), and a genuine CB system (100:0) without added OG was also formulated and used as control. Therefore, the effect of the replacement percentage was studied at a fixed total concentration. To prepare the CB:OG mixed systems, first, the cacao butter pearls were melted by placing them in a thermostatic water bath (Series BD, Bunsen, Madrid, Spain) at $75^{\circ} \mathrm{C}$ to melt all the fat crystals, followed by the immediate cooling of the liquid butter to $60^{\circ} \mathrm{C}$. In turn, the corresponding quantity of OG required for each case was slightly heated to $40^{\circ} \mathrm{C}$ by placing it in another thermostatic water bath (Univeba, JP Selecta, Barcelona, Spain) at this temperature under slight stirring at $300 \mathrm{rpm}$. Following, the melted $\mathrm{CB}$ was slowly added to the OG, also under continuous stirring. The mixtures obtained were finally molded in plastic buckets $(20 \times 30 \mathrm{~mm})$, cooled and stored at refrigeration temperature $\left(4^{\circ} \mathrm{C}\right.$ for $\left.24 \mathrm{~h}\right)$ until further use. To obtain both single systems, the melted CB and the OG were directly molded and stored under identical conditions.

\subsection{Fatty Acids (FAs) Profile of CB:OG Systems}

FA contents of control CB (100:0 system), CB:OG mixed systems (50:50, 40:60, 30:70 and 20:80 systems), pure OG (0:100 system), as well as of HORSO were determined (in triplicate) by saponification and bimethylation using C13:0 as internal standard. Fatty acid methyl ester (FAME) was analyzed by gas chromatography on an Agilent gas chromatograph (Model 7820A, CA-USA) fitted with a GC-28 Agilent DB-23 capillary column $(60 \mathrm{~m} \times 250 \mu \mathrm{m} \times 0.25 \mu \mathrm{m})$, and a flame ionization detector was used. Injector and detector temperatures were 250 and $260^{\circ} \mathrm{C}$, respectively. The temperature profile of the oven was as follows: initially $50^{\circ} \mathrm{C}$ (held for $1 \mathrm{~min}$ ), increasing $25^{\circ} \mathrm{C} / \mathrm{min}$ up to $175^{\circ} \mathrm{C}$ 
and $4{ }^{\circ} \mathrm{C} / \mathrm{min}$ up to $230{ }^{\circ} \mathrm{C}$ (held for $16 \mathrm{~min}$ ). FAs were identified by comparing retention times with a FA standard (47015-U Supelco PUFA No.2 Animal Source, Sigma-Aldrich Co., St. Louis, MO, USA). FAs were expressed as $\mathrm{mg}$ of fatty acid/g sample. Three replicates were performed with samples prepared on two different days.

Based on the FAME results, the atherogenic index (AI) and thrombogenic index (TI) were computed as follows [30]:

$$
\begin{array}{r}
\mathrm{AI}=(\mathrm{C} 12: 0+4 \times \mathrm{C} 14: 0+\mathrm{C} 16: 0) /[\Sigma \mathrm{MUFA}+\Sigma \mathrm{PUFA}(\mathrm{n}-6) \text { and }(\mathrm{n}-3)] \\
\mathrm{TI}=(\mathrm{C} 14: 0+\mathrm{C} 16: 0+\mathrm{C} 18: 0) /(0.5 \times \Sigma \mathrm{MUFA}+0.5 \times \Sigma \mathrm{PUFA}(\mathrm{n}-6)+3 \times \Sigma \mathrm{PUFA}(\mathrm{n}-3)+(\mathrm{n}-3 \mathrm{PUFA}) /(\mathrm{n}-6 \mathrm{PUFA})) .
\end{array}
$$

\subsection{Rheological Measurements}

Rheological measurements of the CB:OG systems were carried out with a rotational Kinexus pro rheometer (Malvern Instruments Ltd., UK) equipped with rSpace of software and a Peltier Plate cartridge in the lower plate for temperature control (resolution to $0.01{ }^{\circ} \mathrm{C}$ ). A plate-plate measuring geometry PU40:PLS61X S3335SS, with smooth upper plate of $40 \mathrm{~mm}$ of diameter and serrated lower plate with $61 \mathrm{~mm}$, was used (1.5-mm gap). Small amplitude oscillation sweeps (SAOS) were performed to analyze the viscoelastic properties of the different systems. All the CB:OG systems were loaded on the rheometer at $20^{\circ} \mathrm{C}$. For this purpose, the control 100:0 system was first melted by placing it in a thermostatic water bath at $75{ }^{\circ} \mathrm{C}$, allowing it to cool down to $20{ }^{\circ} \mathrm{C}$ before loading it on the rheometer. Before measurements at 20 and $10^{\circ} \mathrm{C}$, all systems were allowed to rest on the geometry for $40 \mathrm{~min}$ (to stabilize and restructure the sample) using time sweeps carried out at $1 \mathrm{~Hz}$ with a chosen stress within the linear viscoelastic region (LVR). First, to determine the extent of the LVR, stress amplitude sweeps were carried out at $20{ }^{\circ} \mathrm{C}$ and at $1 \mathrm{~Hz}$ varying the stress from 20 to $2000 \mathrm{~Pa}$, depending on the CB replacement percentage of the system and the measurement temperature. Then, frequency sweeps were performed at $20^{\circ} \mathrm{C}$ between 10 and $0.1 \mathrm{~Hz}$ at chosen stress within the LVR. To observe the effect of cooling the system structure, both stress amplitude and frequency sweeps were also carried out at $10{ }^{\circ} \mathrm{C}$. For this purpose, temperature sweeps were carried out from 20 to $10{ }^{\circ} \mathrm{C}$ at a linear cooling rate of $1^{\circ} \mathrm{C} / \mathrm{min}$, and frequency of $1 \mathrm{~Hz}$ at the chosen stress within the LVR. Finally, to observe the effect of heating the system structure, temperature sweeps were performed from 10 to $60^{\circ} \mathrm{C}$ at a linear heating rate of $1^{\circ} \mathrm{C} / \mathrm{min}$, and at frequency of $1 \mathrm{~Hz}$ within the LVR. Previously, the samples were cooled from 20 to $10{ }^{\circ} \mathrm{C}$ and allowed to rest for $40 \mathrm{~min}$ at both 20 and $10^{\circ} \mathrm{C}$ as indicated above. From all the different tests carried out, the values of storage modulus $\left(G^{\prime}\right)$, loss modulus $\left(G^{\prime \prime}\right)$ and loss tangent $\left(\tan \delta=G^{\prime \prime} / G^{\prime}\right)$ were recorded. All the measurements were repeated at least three times, with samples prepared on different days (two batches) and performed $24 \mathrm{~h}$ after the formulation of the different CB:OG systems.

\subsection{Texture Measurements}

The evaluation of the consistency of the CB:OG systems was carried out using a TA.HDPlus Texture Analyzer (Stable Micro Systems, Ltd., Godalming, UK) provided with Texture Exponent software (version 6.1.16.0; Stable Micro Systems, Ltd., Godalming, UK) and equipped with a $30 \mathrm{~kg}$ load cell. A penetration test was performed using a polyoxymethylene cylindrical probe $(\mathrm{P} / 10,10 \mathrm{~mm} \varnothing)$ that penetrated the sample to a depth of $6 \mathrm{~mm}$ at a rate of $1 \mathrm{~mm} / \mathrm{s}$ with a $0.1 \mathrm{~N}$ trigger force. After $24 \mathrm{~h}$ of storage at $4{ }^{\circ} \mathrm{C}$, the samples were tempered and measured directly in the plastic buckets at both 10 and $20{ }^{\circ} \mathrm{C}$. The maximum force and the area under the force-distance curve at the defined penetration distance were recorded and used as indicators for the consistency/hardness of the CB:OG systems. Three replicates were performed with samples prepared on different days (two batches). 


\subsection{Oil-Binding Capacity}

Oil-binding capacity $(\mathrm{OBC})$ of the $\mathrm{CB} / \mathrm{OG}$ systems was measured by calculating the amount of oil expressed naturally during a defined period of time, based on the procedure described by other authors with some modifications [18,31]. A small sample disc weighing around $10 \mathrm{~g}$ was placed on the center of a piece of filter paper (125 $\mathrm{mm}$ of diameter) and subsequently stored at $4{ }^{\circ} \mathrm{C}$ for $24 \mathrm{~h}$. Oil loss (OL) after 2 and $24 \mathrm{~h}$ at room temperature was calculated as:

$$
\text { OL }(\%)=\frac{\left(\mathbf{W}_{\mathbf{t}}-\mathbf{W}_{\mathbf{0}}\right)}{\mathbf{F}_{\text {system }}}
$$

where OL is the oil loss. $\mathrm{W}_{\mathrm{t}}$ is the filter weight at time $\mathrm{t}(2$ or $24 \mathrm{~h}), \mathrm{W}_{0}$ is the filter weight at time 0 , and $\mathrm{F}_{\text {system }}$ is the fat content of the formulated system. Then, OBC (\%) was calculated as $100-$ OL $(\%)$. Three replicates were performed with samples prepared in two different batches.

\subsection{Statistical Analysis}

For FA composition, one-way analysis of variance (ANOVA) was performed to study the $\mathrm{CB}$ replacement percentage effect. For viscoelastic properties and textural parameters, one-way ANOVA was performed on each property or parameter to study the CB replacement percentage effect within the same temperature $\left(10\right.$ and $\left.20^{\circ} \mathrm{C}\right)$ and the temperature effect within the same CB replacement percentage (0, 50, 60, 70, 80 and 100\%). Identical analyses were conducted for the $\mathrm{OBC}$, but in this case the percentage of replacement of $\mathrm{CB}$ and the time period at room temperature ( 2 and $24 \mathrm{~h}$ ) were the two main effects studied. Significant differences between pairs of means were evaluated by the Tukey test, using a $95 \%$ confidence interval $(p<0.05)$. Analyses were carried out using IBM SPSS statistical for Windows, Version 26.0 (IBM Corp., Armonk, NY, USA).

\section{Results and Discussion}

\subsection{FA Composition of $C B: O G$ Systems}

The fatty acid (FA) composition of the genuine $\mathrm{CB}$, the oil employed to develop the OG (HORSO), the pure OG, as well as the different mixed systems CB:OG, are presented in Table 1.

Predominant FAs in the CB composition (100:0) are stearic, oleic, and palmitic acid, with linoleic acid present in a lesser proportion. This represents SFA and unsaturated fatty acid (UFA) compositions of nearly 60 and $35 \%$ respectively. This agrees with the FA composition of natural CB produced in various countries [32]. Conversely, HORSO is characterized by low SFA and PUFA contents and an elevated quantity of MUFAs ( $>80 \%)$, in particular oleic acid, which corresponds to $79 \%$ of its total FA constituents. As expected, the FA composition of the OG (0:100) is essentially similar to that of HORSO, which was not included in the statistical analysis as it is not a CB:OG system.

The percentage of CB substitution with OG has a significant effect $(p<0.05)$ in the FA composition of the different formulated CB:OG systems. Increasing the OG proportion in the system entails a significant reduction in the SFA content and an increase in unsaturated fats (UFAs), mostly MUFAs and to a lesser extent PUFAs, which is consistent with the composition of the ingredients of the mix. At a nutritional level, the FA composition of $\mathrm{CB}$ is not in line with health recommendations [4], hence, the partial substitution of $\mathrm{CB}$ with the OG (even in the lowest percentage of substitution) is a strategy that provides an ingredient with an improved lipid profile and, thus, could be an adequate replacement for $\mathrm{CB}$ in the formulation of confectionery products. 
Table 1. Fatty acids (FAs) profile in the different formulated CB:OG systems and in high oleic refined sunflower oil (HORSO).

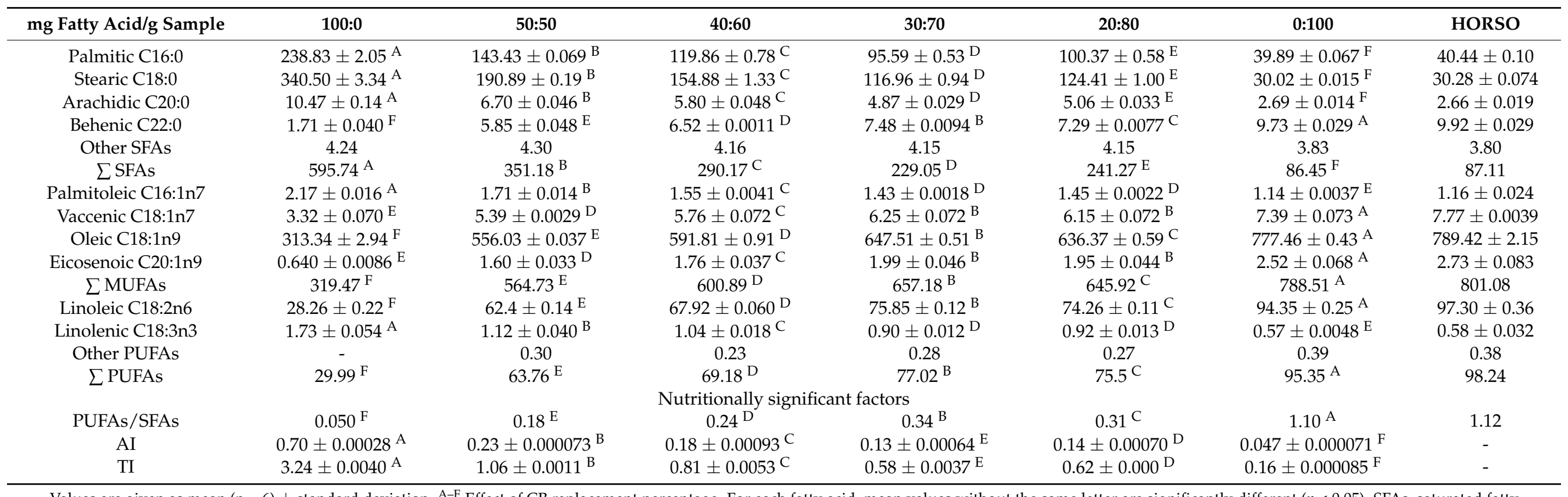

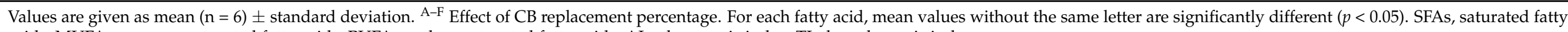
acids; MUFAs, monounsaturated fatty acids; PUFAs, polyunsaturated fatty acids; AI, atherogenic index; TI, thrombogenic index. 
Improvements in the lipid profile observed in the mixed systems CB:OG are associated with the reduction of SFAs, such as palmitic acid, which is associated with the appearance of certain chronic degenerative diseases (cardiovascular disease, some types of cancer, etc.). There is evidence of the relationship between high palmitic acid consumption and an increased level of total cholesterol and low-density lipoprotein (LDL) cholesterol in blood [33]. On the other hand, the improved lipid profile of the systems is linked to a significant increase in oleic acid, which has several known beneficial effects, particularly on cardiovascular health [34]. Nonetheless, it should be noted that although CB has an elevated content of stearic acid, this FA is considered to be neutral in relation to cardiovascular disease, since it neither increases blood cholesterol levels [35], nor contributes to any other thrombogenic risk factor [36].

The nutritional quality of the lipid fraction of foods can be evaluated according to the PUFA/SFA ratio. It has been pointed out that an increase in this proportion can lead to a reduction in plasma total cholesterol, and it is advisable to increase this ratio in different foods [37]. The PUFA/SFA ratio in CB was approximately 0.05 (Table 1), while the strategy of partial and total replacement of $C B$ by the OG lead to a significant increase in the ratio, which was almost 6 times higher in samples with a greater percentage of substitution of $C B$ with the OG (30:70 and 20:80), being closer to the recommended values (>0.4) [38]. Likewise, the atherogenic index (IA) and thrombogenic index (TI) of the systems were determined (Table 1$)$, a significant decrease $(p<0.05)$ of both indexes occurred as the substitution of CB with OG increased, fundamentally due to the reduction in SFAs and increase in UFAs (MUFAs and PUFAs). The difference in the lipid composition of the CB:OG system formulated will affect the rheological and textural properties; a fat crystal network is based on its lipid composition and directly related to its macroscopic properties [39].

\subsection{Linear Viscoelastic Properties of CB:OG Systems}

To study the effect of the internal oil gelation by HPMC on the structural properties of the CB:OG systems, SAOS rheological measurements were carried out. Results were compared to those of the CB single system (100:0 ratio), where only CB provides structure and no OG is present. Stress amplitude sweep tests were initially run to determine the LVR of all the different CB:OG systems. The evolution of $G^{\prime}$ by increasing the applied stress corresponding to systems with 50 and 100\% of CB replacement (50:50 and 0:100 ratios, respectively) in comparison with the control $100: 0$ system at $10{ }^{\circ} \mathrm{C}$ and $20{ }^{\circ} \mathrm{C}$ is shown in (Figure 1). Mixed systems with partial CB replacement ranging between 60 and $80 \%$ (40:60, 30:70 and 20:80 ratios) exhibited decreasing intermediate $G^{\prime}$ values between those of 50:50 and 0:100 formulated systems and narrower LVRs as the percentage of replacement of CB by the OG increased. In the LVR, the gel strength of a sample can be evaluated from the $G^{\prime}$ value in the LVR $\left(G_{\text {LVR }}^{\prime}\right)$ and the viscoelastic limit, i.e., the critical or maximum value of the amplitude sweep (shear stress, $\sigma_{\max }$ ) at which the $G^{\prime}$ value shows a noticeable deviation from the previously constant values $[3,40]$. It is possible to clearly appreciate that both the percentage of replacement of $\mathrm{CB}$ and the measurement temperature had a significant effect on either the $G_{\text {LVR }}^{\prime}$ or the $\sigma_{\max }$ values (data values not shown). Nevertheless, the 50:50 mixed system showed a resistance to the applied stress closer to that of the 100:0 control system than to the 0:100 system. Please note that the 50:50 and 100:0 samples

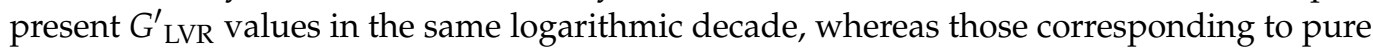
OG (0:100) are almost two decades below.

Even though the increase in the replacement percentage of CB was accompanied by a decrease in the $G^{\prime}{ }_{\text {LVR }}$ value, the presence of a higher quantity of the OG in the system also had a significant effect on the $\sigma_{\max }$ value, and in consequence, on the extension of the LVR. The lowest extent of linear viscoelastic response was found in both temperatures in the 0:100 system, this is, in the pure OG system without CB (Figure 1). In this system, $\sigma_{\text {max }}$ values ranged between approximately 20 and $100 \mathrm{~Pa}$, depending on the measurement

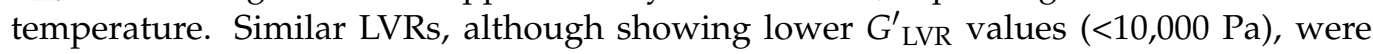
obtained by Patel et al. [17] in oleogels prepared from sunflower oil emulsion in water, 
stabilized with methylcellulose and xanthan gum. According to these authors, the complete extraction of the water phase by drying results in the formation of a structure in which oil drops are found tightly packed in a polysaccharide network. Also, Patel et al. [11] reported a $\sigma_{\max }$ value somewhat higher than that of $100 \mathrm{~Pa}$ obtained in oleogels developed by using the emulsion-templated approach and olive oil, although these authors used a mix of gelatin and xanthan gum as stabilizer as well, and observed an increase in the $\sigma_{\max }$ value with the concentration of both hydrocolloids.

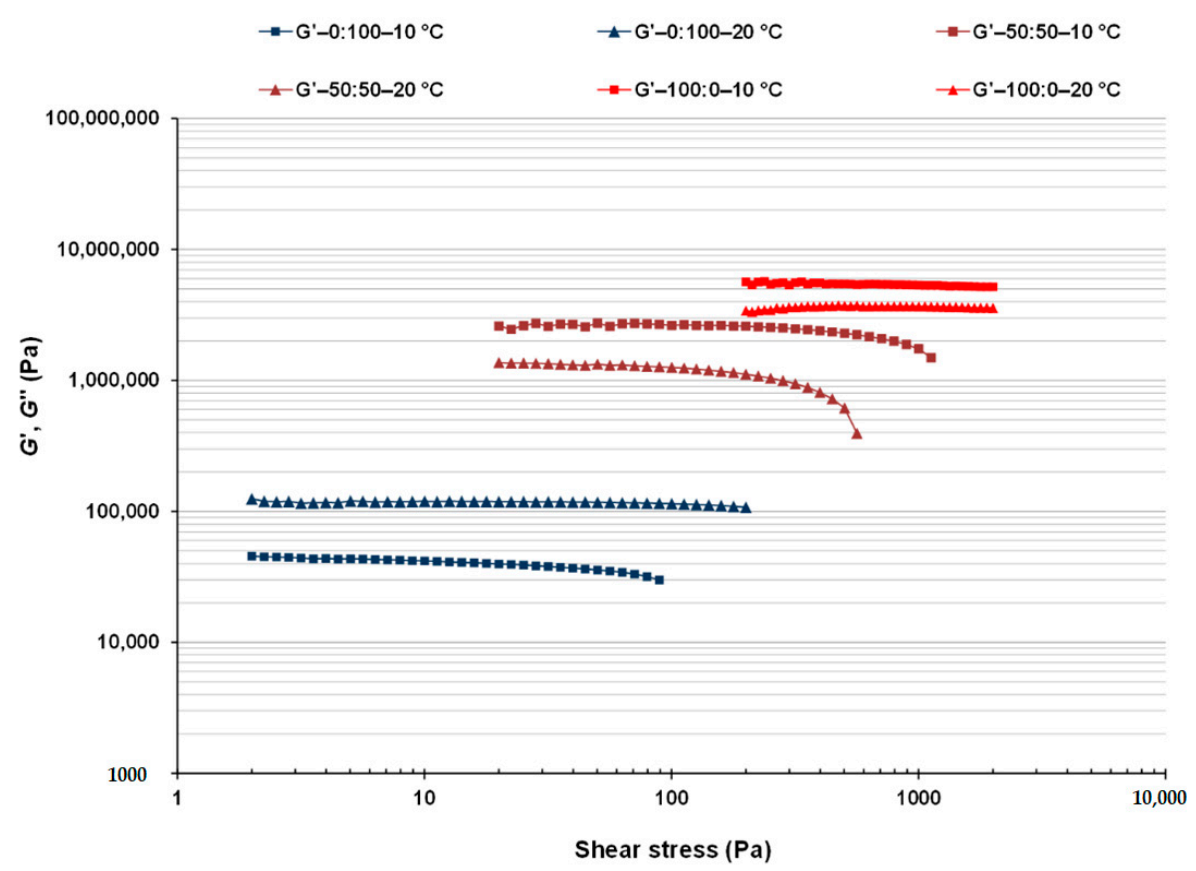

Figure 1. Storage modulus $\left(G^{\prime}\right)$ as a function of the applied shear stress at 100:0, 50:50 and 0:100 formulated systems at 20 and $10^{\circ} \mathrm{C}$.

Compared with the 0:100 system, the 50:50 system shows a notable extension of the LVR with $\sigma_{\max }$ values that are close to $500 \mathrm{~Pa}$ at $10^{\circ} \mathrm{C}$. At the same time, in the 100:0 control system without OG, the $\sigma_{\max }$ values are above $1000 \mathrm{~Pa}$ for both temperatures. This result indicates that fat crystals are the dominating structure that provides a higher resistance against structure degradation for systems constituted by $\mathrm{CB}$ as well as by OG.

Regarding the measurement temperature, and in the presence of $\mathrm{CB}$, the $\mathrm{G}_{\mathrm{LVR}}^{\prime}$ values were higher at 10 than at $20^{\circ} \mathrm{C}$ in all samples, although differences were more noticeable in the 50:50 system (Figure 1). This result is attributed to the more complete crystallization of cacao fat that takes place in the systems at $10^{\circ} \mathrm{C}$. In this context, Bahari and Akoh [28] provided temperatures for the onset and completion points of cacao fat crystallization, determined by differential scanning calorimetry (DSC), of $15.5 \pm 0.1{ }^{\circ} \mathrm{C}$ and of $6.3 \pm 1.1^{\circ} \mathrm{C}$, respectively. On the contrary, in the 0:100 single system, higher sensitivity to the applied stress was observed at 10 than at $20^{\circ} \mathrm{C}$, evidence of a lower resistance against structural degradation at the lower temperature. However, for both temperatures the phase angle of the 0:100 system in the LVR was less than $10{ }^{\circ} \mathrm{C}$, suggesting a phase response to the sinusoidal stress applied that is characteristic of viscoelastic solids [17].

Nevertheless, and though the OG alone presents the lowest $G_{\text {LVR }}^{\prime}$ values and a significantly narrower LVR than the rest of the systems containing $C B$, it must be pointed out that the structural three-dimensional network formed by HPMC provides the necessary structure to show a solid-like behavior, retaining the liquid oil in the developed OG. Meng et al. [13] applied stress sweeps to oleogels elaborated with soy oil using different combinations of HPMC with other thickeners, such as xanthan gum, carboxymethyl cellulose, guar gum, etc. as organogelators. $G_{\text {LVR }}^{\prime}$ values were lower than $1000 \mathrm{~Pa}$ and, in addition, the $\sigma_{\max }$ values were not above $1 \mathrm{~Pa}$ for any of the HPMC combinations with the afore- 
mentioned polysaccharides. The same authors also developed oleogels with xanthan gum $(0.3 \%)$ combined with HPMC in concentrations that ranged from 0.2 to $1 \%$ [14]. Although the increase in HPMC concentration incremented gel resistance in the oleogels, the LVR extension did not exceed $1 \mathrm{~Pa}$ in any of the cases.

Thus, in this study, using an emulsion-templated approach with HORSO, a concentration of HPMC of $1 \%$, and without the use of any additional thickening agent, an OG with a superior stability and a more compact network than any previous one developed by any other author, has been obtained. Yet, and from the variation of the values of storage modulus $\left(G^{\prime}\right)$ versus the shear stress wave amplitude (Figure 1), it is possible to infer that the obtained OG, alone, could not totally replace $\mathrm{CB}$ in confectionery products and confer the same structural properties.

Subsequently, mechanical spectra of the different CB:OG systems were obtained to carry out a linear viscoelastic characterization in function of the frequency. Initially, these spectra of the systems at $20{ }^{\circ} \mathrm{C}$ were obtained by applying a constant stress in the LVR (Figure 2a). However, given the importance of the temperature of crystallization and the size distribution of the fat crystals in products containing CB [24], to study the effect of cooling on the structure of the different systems, the mechanical spectra were also obtained at $10{ }^{\circ} \mathrm{C}$ (Figure $2 \mathrm{~b}$ ).

At $20^{\circ} \mathrm{C}$, and in the 6 formulated CB:OG systems, the $G^{\prime}$ value is higher than that of $G^{\prime \prime}$ in the complete interval of analyzed frequencies (Figure 2a), and with just a small frequency dependence mainly of the elastic or storage modulus $G^{\prime}$, which was slightly more and less perceptible in the systems elaborated with OG and $\mathrm{CB}$ alone, respectively.

This low frequency dependence of both viscoelastic moduli would indicate the existence of a strong internal network in all systems [8]. In addition, $G^{\prime}$ values in the 100:0 control system present a difference of almost a logarithmic decade with respect the values corresponding to the 50:50 system, which is of about three logarithmic decades if compared with the system based on OG alone (0:100). A solid-like mechanical behavior is characterized by a $G^{\prime}$ which is far larger than $G^{\prime \prime}$ and both moduli are independent of frequency [41], as found in the 100:0 system. However, the 0:100 system showed a structured liquid behavior in which $G^{\prime}$ is also larger than $G^{\prime \prime}$, but both moduli are slightly dependent on frequency, which is characteristic of gels where one of the components is a liquid present in a substantial quantity, as is the case of the oil retained in the OG developed. In turn, the CB:OG mixed systems exhibited an intermediate state that resembles a behavior of structured soft solid as the replacement percentage of CB by the OG increased (Figure 2a). Hence, a clear effect of the concentration of both ingredients on the values of the rheological properties of the CB:OG systems can be observed.

At $10{ }^{\circ} \mathrm{C}$, the shape and distribution of the mechanical spectra obtained for the CB:OG systems (Figure $2 \mathrm{~b}$ ) are very similar to the corresponding ones at $20^{\circ} \mathrm{C}$, and even though the highest $G^{\prime}$ and $G^{\prime \prime}$ values also corresponded to the control system elaborated without OG, there is scarcely any difference in the $G^{\prime}$ values of the 50:50 and 40:60 systems, being the case that for all the systems $G^{\prime}$ values are closer at 10 than at $20^{\circ} \mathrm{C}$. Conversely, the mechanical spectrum of the pure $\mathrm{OG}$ at $10{ }^{\circ} \mathrm{C}$ is more separated from the corresponding spectra of the mixed systems at $20^{\circ} \mathrm{C}$.

At the same time, $G^{\prime}, G^{\prime \prime}$ and $\tan \delta$ values of the formulated CB:OG systems associated with a frequency of $1 \mathrm{~Hz}$, and obtained at both temperatures, 10 and $20^{\circ} \mathrm{C}$, are gathered in (Table 2). The one-way ANOVAs indicated that the replacement percentage of CB had itself a relevant effect in the three rheological properties at 20 as well as at $10^{\circ} \mathrm{C}$. At both temperatures, and compared with the 100:0 control, $G^{\prime}$ and $G^{\prime \prime}$ values dropped significantly as the percentage of substitution of $\mathrm{CB}$ with the $\mathrm{OG}$ increased. At $20^{\circ} \mathrm{C}$ only the $G^{\prime}$ and $G^{\prime \prime}$ values for the 30:70 system are greater than the ones for the 40:60 system, and their $\tan \delta$ values are also lower. In turn, at $10^{\circ} \mathrm{C}$, there are essentially no significant differences among the $\tan \delta$ values of the systems elaborated with a partial substitution of $\mathrm{CB}$. At 20 and $10{ }^{\circ} \mathrm{C}$ the highest values for $G^{\prime}(6630 \pm 83.5 \mathrm{kPa}$ and $7281 \pm 848 \mathrm{kPa}$, respectively) and $G^{\prime \prime}(339 \pm 12.7 \mathrm{kPa}$ and $305 \pm 69.2 \mathrm{kPa})$, as well as the lowest $\tan \delta$ values 
( $0.051 \pm 0.001$ and $0.042 \pm 0.011$, respectively) correspond to the genuine CB (Table 2), which reflects that the $\mathrm{CB}$ system, at either temperature, presents an internal network that is stronger, more cohesive, and showing higher connectivity than the rest of the systems with growing percentages of OG. Certainly, the 100:0 control system contains fat crystals that generate an internal highly ordered three-dimensional network which provides high resistance and hardness to the structure [24]. According to Bahari and Akoh [24], CB crystallizes in a polymorphic $\beta$ structure responsible for a melting point close to the body temperature, and in morphological terms, CB presents a mix of granular crystals and small spherules that are associated with its high SFA content (Table 1). The polymorphic behavior of $\mathrm{CB}$ has been studied by some investigators [24,28], and, even in the presence of sunflower oil [21], it is determined by its high solid fat content (SFC) and specific composition of TAGs. Chai et al. [39] have also reported that the thickness of the nanoscale-crystals decreases significantly with a higher SFC. In contrast, the crystalline nucleus of fats presents a slower velocity of crystallization and growth in the CB:OG mixed systems that have a lower SFC.
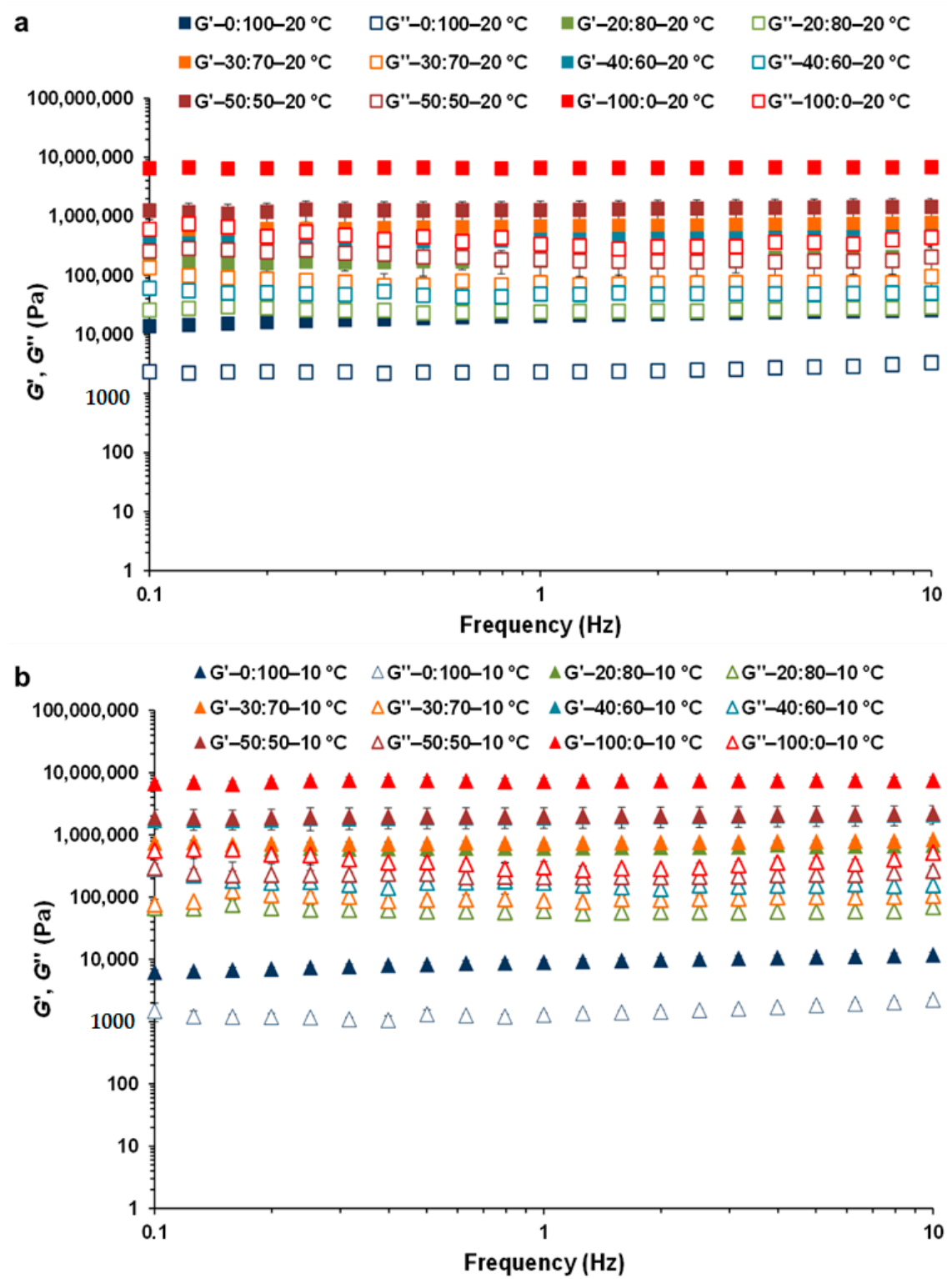

Figure 2. Storage modulus ( $G^{\prime}$ : filled symbols) and loss modulus ( $G^{\prime \prime}$ : open symbols) as a function of oscillation frequency for the different formulated CB:OG systems: $(\mathbf{a})$ at $20^{\circ} \mathrm{C} ;(\mathbf{b})$ at $10^{\circ} \mathrm{C}$. 
Table 2. Viscoelastic properties at $1 \mathrm{~Hz}$ and at 20 and $10{ }^{\circ} \mathrm{C}$ derived from frequency sweeps for the different formulated CB:OG systems.

\begin{tabular}{|c|c|c|c|c|c|c|}
\hline \multirow{2}{*}{ CB:OG } & \multicolumn{3}{|c|}{$20^{\circ} \mathrm{C}$} & \multicolumn{3}{|c|}{$10^{\circ} \mathrm{C}$} \\
\hline & $G^{\prime}(\mathbf{k P a})$ & $G^{\prime \prime}(\mathbf{k P a})$ & $\operatorname{Tan} \delta$ & $G^{\prime}(\mathbf{k P a})$ & $G^{\prime \prime}(\mathbf{k P a})$ & $\operatorname{Tan} \delta$ \\
\hline 100:0 & $6630 \pm 84^{\mathrm{Aa}}$ & $339 \pm 13^{\mathrm{Aa}}$ & $0.051 \pm 0.0013^{\mathrm{Da}}$ & $7281 \pm 848^{\mathrm{Aa}}$ & $305 \pm 69$ Aa & $0.042 \pm 0.011 \mathrm{Da}$ \\
\hline $50: 50$ & $1291 \pm 20^{\mathrm{Bb}}$ & $184 \pm 16^{\text {Ва }}$ & $0.11 \pm 0.0039 \mathrm{Ca}$ & $1999 \pm 25^{\mathrm{Ba}}$ & $210 \pm 13^{\mathrm{Aa}}$ & $0.090 \pm 0.015^{\mathrm{Cb}}$ \\
\hline $40: 60$ & $399 \pm 35^{\mathrm{Db}}$ & $48.5 \pm 8.9^{\mathrm{Db}}$ & $0.12 \pm 0.012$ B, Ca & $1900 \pm 61^{\mathrm{Ba}}$ & $172 \pm 26^{\mathrm{A}, \mathrm{Ba}}$ & $0.11 \pm 0.0079 \mathrm{~B}, \mathrm{Cb}$ \\
\hline $30: 70$ & $677 \pm 2.3^{\mathrm{Cb}}$ & $75.2 \pm 2.6^{\mathrm{Cb}}$ & $0.11 \pm 0.0029 \mathrm{Ca}$ & $732 \pm 32 \mathrm{Ca}$ & $87.9 \pm 7.14$ B, Ca & $0.12 \pm 0.0048 \mathrm{~A}, \mathrm{Ba}$ \\
\hline $20: 80$ & $178 \pm 15^{\mathrm{Eb}}$ & $24.0 \pm 3.0^{\mathrm{D}, \mathrm{Eb}}$ & $0.14 \pm 0.0048^{\mathrm{A}, \mathrm{Ba}}$ & $619 \pm 27 \mathrm{Ca}$ & $60.9 \pm 1.59 \mathrm{C}, \mathrm{Da}$ & $0.098 \pm 0.0021^{\mathrm{B}, \mathrm{Cb}}$ \\
\hline $0: 100$ & $20.8 \pm 1.3^{\mathrm{Fa}}$ & $2.33 \pm 0.16^{\mathrm{Ea}}$ & $0.14 \pm 0.010^{\mathrm{Aa}}$ & $9.04 \pm 0.49 \mathrm{Cb}$ & $1.29 \pm 0.084^{\mathrm{Db}}$ & $0.14 \pm 0.0019^{\mathrm{Aa}}$ \\
\hline
\end{tabular}

Values are given as mean $(n=6) \pm$ standard deviation. ${ }^{A-F}$ Effect of $C B$ replacement percentage. For each rheological property and the same temperature $\left(20\right.$ and $\left.10^{\circ} \mathrm{C}\right)$, mean values without the same letter are significantly different $(p<0.05)$. ${ }^{a}, \mathrm{~b}$ Effect of measurement temperature. For each rheological property and the same $\mathrm{CB}$ replacement percentage $(0,50,60,70,80$ and $100 \%)$, mean values without the same letter are significantly different $(p<0.05)$. $G^{\prime}$, storage modulus; $G^{\prime \prime}$, loss modulus; $\tan \delta$, loss tangent $\left(=G^{\prime \prime} / G^{\prime}\right)$.

On the other hand, the softer structure is that of the 0:100 system, elaborated without $\mathrm{CB}$, with $G^{\prime}$ values of $20.8 \pm 1.25 \mathrm{kPa}$ and $9.04 \pm 0.494 \mathrm{kPa}$ and $G^{\prime \prime}$ values of $2.33 \pm 0.158 \mathrm{kPa}$ and $1.29 \pm 0.084 \mathrm{kPa}$ at 20 and $10^{\circ} \mathrm{C}$, respectively. However, in the 50:50 system, although $G^{\prime}$ values are also significantly lower than those of the 100:0 control at both temperatures, the existing differences are much smaller, and even at $10{ }^{\circ} \mathrm{C}$ there are no significant variations between the $G^{\prime \prime}$ values corresponding to the 50:50 and 100:0 systems (Table 2). The results also reflect that in the systems elaborated with $C B$ and $O G$, the fat crystals of $\mathrm{CB}$ are the dominant structure reinforcing the $\mathrm{OG}$, and their rigidity increases as the OG concentration diminishes. The results, hence, corroborate that SFAs contribute by providing more solidity to fat, whereas the opposite is true in the case of fats with a high UFA content [1].

Regarding the measuring temperature in each formulated system, although in the 100:0 control $G^{\prime}$ and $\tan \delta$ values at $10^{\circ} \mathrm{C}$ are higher and lower respectively than at $20^{\circ} \mathrm{C}$, the differences are minor (Table 2), while these same differences proved to be significant in the case of the 50:50 system. At the same time, in the 40:60, 30:70 and 20:80 mixed systems, $G^{\prime}$ values as well as $G^{\prime \prime}$ values were significantly higher at 10 than at $20^{\circ} \mathrm{C}$, as was the case for systems 40:60 and 20:80, where tan $\delta$ values were also significantly lower at $10^{\circ} \mathrm{C}$. In the pure OG temperature had a significant effect on $G^{\prime}$ and $G^{\prime \prime}$ values as well. Nonetheless, in absence of $C B G^{\prime}$ and $G^{\prime \prime}$ were higher at 20 than at $10^{\circ} \mathrm{C}$, although the viscoelasticity of the system $(\tan \delta)$ did not suffer any variation with temperature. In reference to this last rheological property, $\tan \delta$ values are below 0.1 for both the 100:0 control system at 10 and $20^{\circ} \mathrm{C}$, and the $50: 50$ system at $10^{\circ} \mathrm{C}$, therefore they can be characterized as strong gels [41]. Nonetheless, it should be noted that in all systems, including 0:100 for pure OG, $\tan \delta$ values are very low and below 0.15 .

In addition, it is interesting to reiterate that the 0:100 system developed with the OG alone, exhibits $G^{\prime}$ and $G^{\prime \prime}$ values greater than those of any other oleogel, found in the literature, and formulated with a cellulose ether combined with a thickening agent. For instance, oleogels elaborated with HPMC and xanthan gum showed $G^{\prime}$ values at $1 \mathrm{~Hz}$ and at $25^{\circ} \mathrm{C}$ that were below $1 \mathrm{kPa}$ [14,15], while in methylcellulose and xanthan gum [17], and gelatin and xanthan gum oleogels [11], these values were below $10 \mathrm{kPa}$. Likewise, Jiang et al. [21] obtained oleogels also by an emulsion-templated approach, but from regenerated cellulose and carboxymethyl cellulose, obtaining $G^{\prime}$ values close to $15 \mathrm{kPa}$. All these $G^{\prime}$ values are inferior to the ones obtained for the 0:100 system at $20^{\circ} \mathrm{C}$ (Table 2).

As mentioned above, to study the cooling effect in the structure of the CB:OG systems it was necessary to previously perform temperature sweeps from 20 to $10{ }^{\circ} \mathrm{C}$. Figure 3 shows the evolution of $G^{\prime}$ and $G^{\prime \prime}$ values from a temperature of 20 to $10^{\circ} \mathrm{C}$ in the different CB:OG systems, while (Table S1) has $G^{\prime}, G^{\prime \prime}$ and $\tan \delta$ values at 20,15 and $10^{\circ} \mathrm{C}$ obtained from these coolings. It can be appreciated in (Figure 3) that $G^{\prime}$ and $G^{\prime \prime}$ values of the 100:0 control and the 0:100 pure OG systems, remain almost constant between 20 to 
$10{ }^{\circ} \mathrm{C}$, as opposed to the viscoelastic properties corresponding to the mixed CB:OG systems, which are much more sensitive to the temperature coolings performed, and increase significantly as the temperature goes down. This fact is associated with the hardening of the system structure because of the solidification of the cacao fat crystals, which leads to the formation of an internal three-dimensional network of crystals that is more structured and has greater consistency [8]. Bahari and Akoh [24] observed that the crystallization onset temperature for $\mathrm{CB}$ fat was $15.5^{\circ} \mathrm{C}$, and slightly superior $\left(16.1-18.2^{\circ} \mathrm{C}\right)$ for different $\mathrm{CB}$ equivalents synthesized by enzymatic interestification. However, and although it cannot be observed in (Figure 3), $G^{\prime}$ and $G^{\prime \prime}$ values in the 100:0 system also increased during cooling to $10{ }^{\circ} \mathrm{C}$ (Table S1) due to the strengthening of its network structure linked to the temperature decrease.

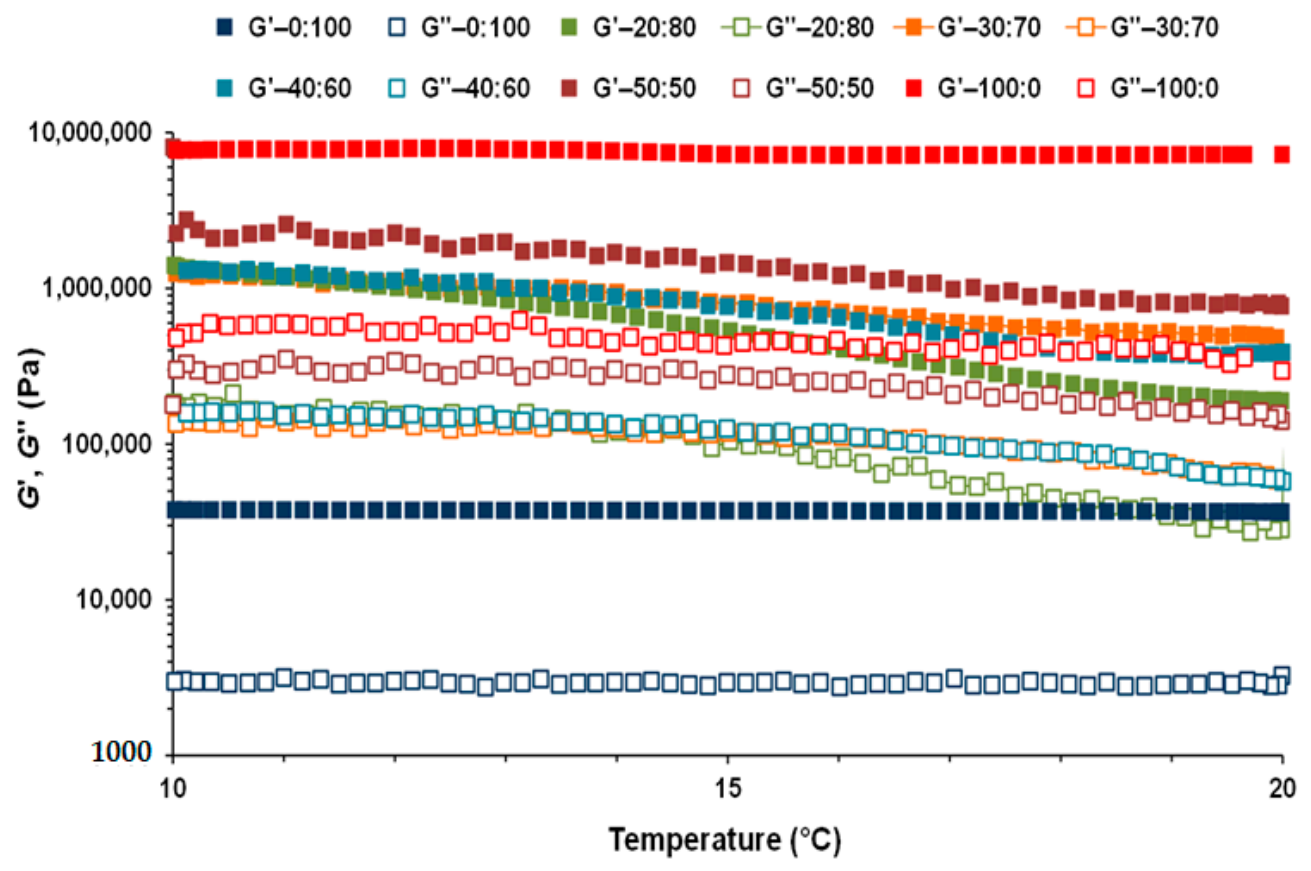

Figure 3. Storage modulus ( $G^{\prime}$ : filled squares) and loss modulus ( $G^{\prime \prime}$ : open squares) as a function of temperature 20 and $10{ }^{\circ} \mathrm{C}$ for the different formulated CB:OG systems.

At 20, 15 and $10{ }^{\circ} \mathrm{C}$ the replacement percentage of CB had a significant effect on three viscoelastic properties values presented in (Table S1), decreasing both $G^{\prime}$ and $G^{\prime \prime}$ as the replacement percentage of $\mathrm{CB}$ by the $\mathrm{OG}$ increased. Also, regarding the measuring temperature of each formulated system, in both the 100:0 and the 0:100 systems, this factor did not show a relevant effect on the values of the viscoelastic properties (Figure 3; Table S1). Conversely, in the 50:50, 40:60, 30:70 and 20:80 systems the measuring temperature had a significant effect on the $G^{\prime}, G^{\prime \prime}$ and $\tan \delta$ values, increasing both moduli and decreasing loss factor when lower in temperature.

Another very important aspect that characterizes the functionality of the formulated CB:OG systems is their thermorheological behavior, since it provides important structural information for its applicability in product formulations. In fact, a typical characteristic of $\mathrm{CB}$ and cocoa derivatives is their melting profile. Thus, to observe the concurring changes in the structure and detect the melting points (cross-over temperature for $G^{\prime}$ and $\left.G^{\prime \prime}\right)$ of the different CB:OG systems, temperature sweeps were also performed for dynamic thermomechanical analysis (DTMA) from 10 to $60^{\circ} \mathrm{C}$ in the LVR (Figure 4). It is possible to observe how in the 0:100 system, $G^{\prime}$ and $G^{\prime \prime}$ values were kept constant from 10 to $60{ }^{\circ} \mathrm{C}$. Similar results were obtained by Tavernier et al. [3] in oleogels prepared with soy protein isolate, submitted to DTMA from 5 to $80^{\circ} \mathrm{C}$, and by Patel et al. [16] in oleogels containing HPMC and xanthan gum and subjected to heating from 10 to $70{ }^{\circ} \mathrm{C}$. This result reflects that the network structure of the developed OG in this study is very thermostable 
against heating. Evidently, by drying at $60^{\circ} \mathrm{C}$, eliminating the water from the sunflower oil emulsion stabilized with HPMC creates a network structure in which the oil drops remain tightly packed, and, at the same time, this structure lasts after shearing to obtain the OG, preventing oil release and corroborating previous studies [11,18,21].

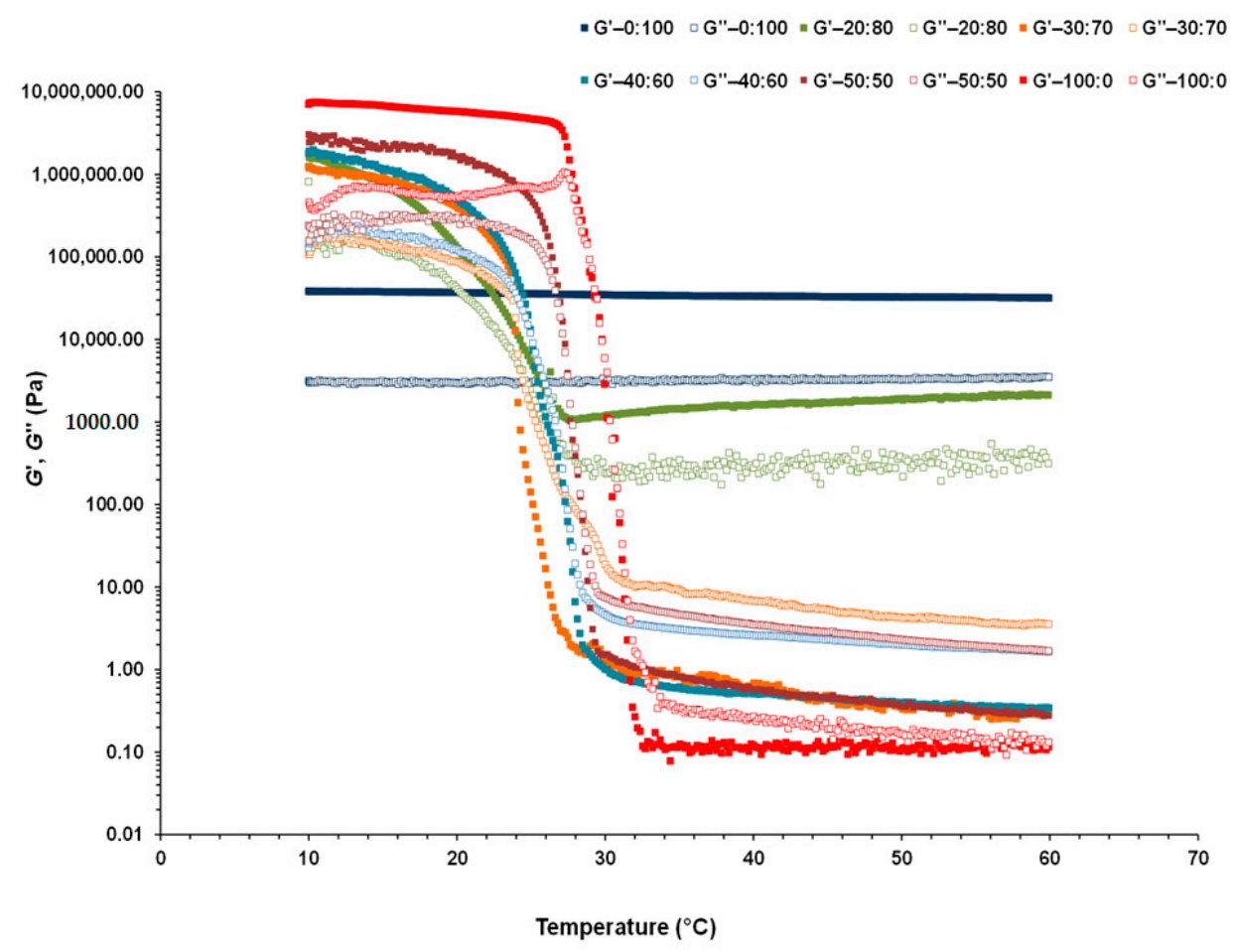

Figure 4. Storage modulus ( $G^{\prime}$ : filled squares) and loss modulus ( $G^{\prime \prime}$ : open squares) as a function of temperature during heating between 10 and $60^{\circ} \mathrm{C}$ for the different formulated CB:OG systems.

However, compared with the 0:100 system, in the formulations where CB is the fat source it is possible to distinguish two types of behavior as temperature is increased, as this behavior is also a function of the replacement percentage of $\mathrm{CB}$ by the $\mathrm{OG}$ in the system. Thus, the thermorheological behavior of the $20: 80$ system $(20 \%$ CB and $80 \%$ OG) was significantly different to that of the 0:100 system without $C B$, as well as of the rest of the systems with lower OG percentages (Figure 4). In the 20:80 system, from 10 to $30^{\circ} \mathrm{C}$ the $G^{\prime}$ and $G^{\prime \prime}$ values drop abruptly, although they do not cross, and both $G^{\prime}$ and $G^{\prime \prime}$ values show a slight increase from 30 to $60^{\circ} \mathrm{C}$. Therefore, in this system the elastic structure of the OG is still dominant, showing a structured soft solid-like thermomechanical behavior with $G^{\prime}$ values above those of $G^{\prime \prime}$ all throughout the heating process.

In contrast, in the systems containing a higher amount of $\mathrm{CB}$, the thermorheological behavior was very different (Figure 4). In the 100:0, 50:50, 40:60 and 30:70 systems, initially, a severe decrease in both moduli can be observed in the first stages of heating, followed by a cross-over of the $G^{\prime}$ and $G^{\prime \prime}$ values connected to the melting of the CB fat crystals, and finally the systems show a liquid-like behavior as demonstrated by $G^{\prime \prime}$ values higher than those of $G^{\prime}$. This might be because more crystalline TAGs melted at a higher temperature and resulted in a lower SFC and less crystal aggregation [39]. In addition, a strong correlation can be observed between $G^{\prime}$ and $G^{\prime \prime}$ values and the quantity of OG added in the CB:OG systems (Figure 4). As SFC decreases by increasing OG incorporation, a higher proportion of the product is solid between 30 and $60^{\circ} \mathrm{C}$.

Table 3 shows the average values of the viscoelastic moduli corresponding to 10, 20, 30 and $40{ }^{\circ} \mathrm{C}$ for the different CB:OG systems, as well as the temperature in which the crossover between $G^{\prime}$ and $G^{\prime \prime}$ values occurs in the samples, given that such cross-over takes place. The cross-over temperature of the viscoelastic moduli can be considered to be a melting point 
measurement obtained by DSC [31]. In all the formulated systems $G^{\prime}$ and $G^{\prime \prime}$ values at 50 and $60{ }^{\circ} \mathrm{C}$ were very similar to those obtained at $40^{\circ} \mathrm{C}$ (Figure 4 ), and consequently, they are not presented in (Table 3). At 10,20,30 and $40^{\circ} \mathrm{C}$ the replacement percentage of $\mathrm{CB}$ by the OG had a significant effect in the values of both $G^{\prime}$ y $G^{\prime \prime}$. As expected, at 10 and $20^{\circ} C_{,} G^{\prime}$ and $G^{\prime \prime}$ values decrease significantly as the percentage of $O G$ in the systems increases, On the contrary, at 30 and $40{ }^{\circ} \mathrm{C}$ the highest $G^{\prime}$ values correspond to the most thermostable system, 0:100, constituted by pure OG (Table 3). Additionally, just in the pure OG system, the measuring temperature did not have a relevant effect on the viscoelastic moduli. On the other hand, the average temperature corresponding to the $G^{\prime}$ and $G^{\prime \prime}$ cross-over was that of $29^{\circ} \mathrm{C}$ in the 100:0 control system and, compared with the genuine $C B$, this temperature decreased significantly in the systems with a partial replacement of 50,60 and 70\% of CB by the OG (Table 3). These results reflect that as the SFC increases in the system by decreasing the OG proportion, the process requires more energy to melt more crystalline fat compared with the CB:OG systems with a higher OG content.

The differences in melting temperatures between the genuine $\mathrm{CB}$ and all the different $\mathrm{CB}: \mathrm{OG}$ mixed formulations give insight into the behavior of the mixtures as a system. If there was no interaction between $\mathrm{CB}$ and oil droplets, $\mathrm{CB}$ melting temperature would be the same in the CB:OG mixed systems and the control 100:0 one. However, the melting profile of each CB:OG mixed system is shifted lower in temperature by increasing the OG content (Figure 4). This shift indicates an interaction between the oil droplets and the CB, producing the softening effect observed. It would appear that the slight stirring applied during the preparation of the CB:OG mixed systems supplies enough energy to produce fat globules within the oily phase provided by the OG, and possibly emulsified by HPMC. Similar results were reported by McGill and Hartel [42] from melting profiles using DSC for chocolate and ganache formulations made with different ratios of milk fat procured from cream and butter. The cited authors also found that in both ganache and chocolate, melting enthalpies decreased with decreased SFC.

Bahari and Akoh [24] obtained by DSC onset and completion melting temperatures of the fat crystals in $\mathrm{CB}$ at 30.9 and $38.6^{\circ} \mathrm{C}$, respectively. As well, onset and completion melting temperatures also obtained by DSC in chocolate were 29.6 and $38.6^{\circ} \mathrm{C}$, respectively [42]. Hence, the $29^{\circ} \mathrm{C}$ corresponding to the $100: 0$ system cross-over, are quite proximal to the melting temperature for $\mathrm{CB}$ documented by other authors.

\subsection{Texture Measurements of CB:OG Systems}

To understand the resistance that the CB:OG systems present against large deformations, their mechanical properties were determined at 10 and $20{ }^{\circ} \mathrm{C}$ by a penetration test. Figure 5 shows the texture profiles (force-distance curves) corresponding to the different CB:OG systems formulated. At both temperatures, the 0:100, 20:80, 30:70 and 40:60 systems with a higher percentage of OG presented force/distance profiles distinctive of a compact but malleable gel structure, in which force increases with the distance travelled by the probe, and peaks indicating the breakdown of the structure are not observed, nor does a final drop of the force increase with distance. However, at $10^{\circ} \mathrm{C}$, both the 100:0 control and the 50:50 mixed systems with a higher content of cocoa solids (Figure 5a) showed very different profiles with a first force peak that was reached almost immediately after sample penetration, which reflects an initial rupture of the structure that was concurrent with the characteristic "snap" of chocolate and by a final force drop. This last sound, together with high hardness, is a desirable attribute in chocolate [28]. In the 100:0 samples at $20{ }^{\circ} \mathrm{C}$ (Figure $5 \mathrm{~b}$ ), one or various peaks related to structural rupturing during probe penetration were detected, and they, as well, were concurrent with the aforementioned "snaps", although not in such a distinctive manner as observed at $10{ }^{\circ} \mathrm{C}$. At $20{ }^{\circ} \mathrm{C}$ the structure of the 100:0 control system is not as brittle as at $10^{\circ} \mathrm{C}$, since some TAGs start melting at this point and, consequently, less work is required to deform the system at a higher temperature [6]. 
Table 3. Viscoelastic properties derived from dynamic thermomechanical analysis (DTMA) carried out between 10 and $60{ }^{\circ} \mathrm{C}$ for the different formulated CB:OG systems.

\begin{tabular}{|c|c|c|c|c|c|c|c|c|c|}
\hline \multirow{2}{*}{ CB:OG } & \multirow{2}{*}{$\begin{array}{c}10^{\circ} \mathrm{C} \\
G^{\prime}(\mathrm{kPa})\end{array}$} & \multicolumn{3}{|c|}{$20^{\circ} \mathrm{C}$} & \multirow{2}{*}{$\begin{array}{c}30^{\circ} \mathrm{C} \\
G^{\prime}(\mathrm{kPa})\end{array}$} & \multicolumn{3}{|c|}{$40^{\circ} \mathrm{C}$} & \multirow{2}{*}{$\begin{array}{c}\text { Temperature } \\
\text { Cross-Over }\left({ }^{\circ} \mathrm{C}\right.\end{array}$} \\
\hline & & $G^{\prime \prime}(\mathbf{k P a})$ & $G^{\prime}(\mathbf{k P a})$ & $G^{\prime \prime}(\mathbf{k P a})$ & & $G^{\prime \prime}(\mathrm{kPa})$ & $G^{\prime}(\mathbf{k P a})$ & $G^{\prime \prime}(\mathrm{kPa})$ & \\
\hline 100:0 & $7245^{\text {Аa }}(143)$ & 459 Аа (122) & $5764^{\mathrm{Ab}}(182)$ & $547^{\mathrm{Aa}}(62)$ & $3.29 \mathrm{Bc}(1.2)$ & $7.06^{\mathrm{Ab}}(0.53)$ & $\begin{array}{l}0.00012^{\mathrm{Bc}} \\
(0.000095)\end{array}$ & $\begin{array}{l}0.00027 \mathrm{Cb} \\
(0.0000074)\end{array}$ & $29.0^{\mathrm{A}}(0.10)$ \\
\hline $50: 50$ & $3276^{\mathrm{Ba}}(269)$ & $277^{\mathrm{Ba}}(42)$ & $1405^{\mathrm{Bb}}(121)$ & 272 Ba $(20)$ & $\begin{array}{c}0.00066^{\mathrm{Bc}} \\
(0.00014)\end{array}$ & $\begin{array}{l}0.0038^{\mathrm{Cb}} \\
(0.00052)\end{array}$ & $\begin{array}{c}0.00027^{B c} \\
(0.00011)\end{array}$ & $\begin{array}{l}0.0018^{\mathrm{Cb}} \\
(0.00029)\end{array}$ & $27.3^{\mathrm{B}}(0.47)$ \\
\hline $40: 60$ & $2096^{\mathrm{Ca}}(205)$ & $154^{\mathrm{B}, \mathrm{Ca}}(10)$ & $653^{\mathrm{Cb}}(136)$ & $138^{\mathrm{Ca}}(22)$ & $\begin{array}{l}0.0016^{\mathrm{Bc}} \\
(0.00096)\end{array}$ & $\begin{array}{c}0.0072 \mathrm{Cb} \\
(0.0031)\end{array}$ & $\begin{array}{l}0.00035^{\mathrm{BC}} \\
(0.000092)\end{array}$ & $\begin{array}{l}0.0022 \mathrm{Cb} \\
(0.00038)\end{array}$ & $24.3^{\mathrm{D}}(0.61)$ \\
\hline $30: 70$ & $1803^{\mathrm{Ca}}(109)$ & $129^{\mathrm{C}, \mathrm{Da}}(2.7)$ & $521^{\mathrm{Cb}}(30)$ & $118^{\mathrm{C}, \mathrm{Da}}(11)$ & $\begin{array}{l}0.00089 \mathrm{Bc} \\
(0.000054)\end{array}$ & $0.062^{\mathrm{Cb}}(0.0066)$ & $\begin{array}{l}0.00144^{\mathrm{Bc}} \\
(0.00034)\end{array}$ & $0.034^{\mathrm{Cb}}(0.0030)$ & $25.5^{\mathrm{C}}(0.31)$ \\
\hline $20: 80$ & $1605^{\mathrm{Ca}}(248)$ & $236^{\mathrm{B}, \mathrm{Ca}}(23)$ & $127^{\mathrm{Db}}(16)$ & $40.3^{\mathrm{D}, \mathrm{Eb}}(9.3)$ & $1.18^{\mathrm{Bb}}(0.0075)$ & $0.24^{\mathrm{Cc}}(0.13)$ & $1.62^{\mathrm{Bb}}(0.080)$ & $0.28^{\mathrm{Bc}}(0.019)$ & - \\
\hline $0: 100$ & $38.1^{\mathrm{Da}}(1.8)$ & $3.04^{\mathrm{Da}, \mathrm{b}}(0.16)$ & $36.9^{\mathrm{Da}}(3.5)$ & $2.94 \mathrm{~Eb}(0.097)$ & $34.6^{\text {Aa }}(3.8)$ & $3.18^{\mathrm{Ba}, \mathrm{b}}(0.13)$ & $33.4^{\mathrm{Aa}}(4.03)$ & $3.34^{\mathrm{Aa}}(0.14)$ & - \\
\hline
\end{tabular}

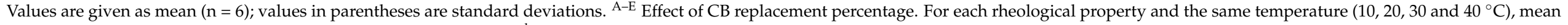

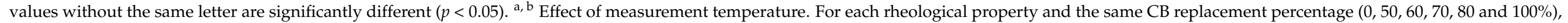
mean values without the same letter are significantly different $(p<0.05)$. $G^{\prime}$, storage modulus; $G^{\prime \prime}$, loss modulus; $\tan \delta$, loss $\operatorname{tangent}\left(=G^{\prime \prime} / G^{\prime}\right)$. 

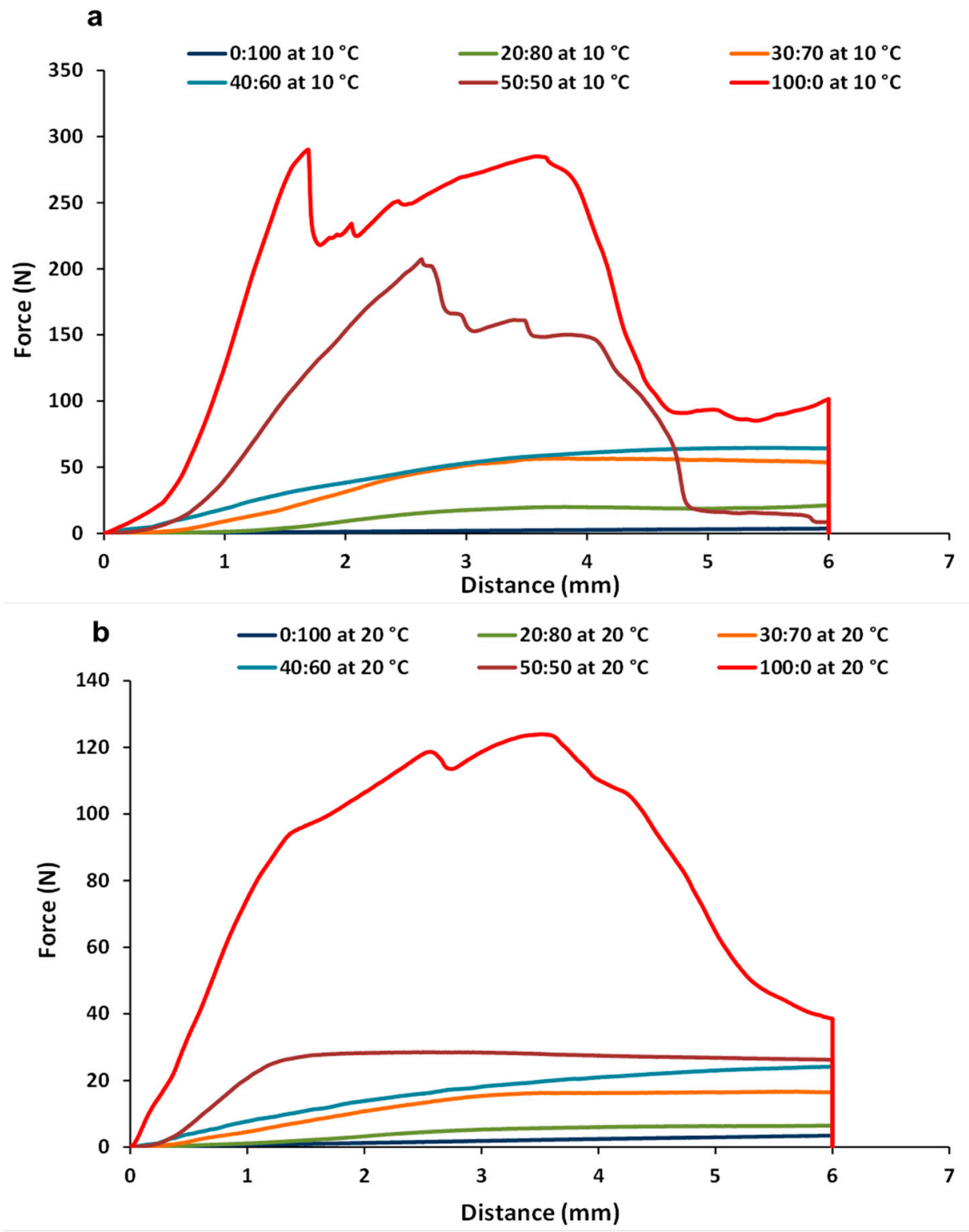

Figure 5. Force-distance curves of the different formulated CB:OG systems measured: (a) at $10^{\circ} \mathrm{C}$; (b) at $20^{\circ} \mathrm{C}$.

The textural parameter derived from the curves force-distance corresponding to the CB:OG formulated systems and determined at 10 and $20^{\circ} \mathrm{C}$ are presented in (Table 4). At both temperatures, the replacement percentage of $C B$ by the OG has a significant effect on both textural parameter values, which diminish progressively as the OG percentage increases in the system. Again, the differences in SFC of the mixed systems would explain why formulations with more CB (more SFC) were harder than those with more OG. Both the oily and dispersed (globules of fat) phases influence textural properties of the CB:OG mixed systems. Higher levels of crystalline fat in the dispersed phase resulted in firmer systems, as previously observed from the textural properties of ganache and caramel $[42,43]$. A stronger hardness has been also associated with higher SFC and a denser aggregation in fat crystal networks [39]. 
Table 4. Textural penetration parameters obtained at 10 and $20^{\circ} \mathrm{C}$ for the different formulated CB:OG systems.

\begin{tabular}{|c|c|c|c|c|}
\hline CB:OG & $\begin{array}{l}\text { Maximum } \\
\text { Force (N) }\end{array}$ & $\begin{array}{c}\text { AUC } \\
(\mathrm{N} \times \mathbf{m m})\end{array}$ & $\begin{array}{l}\text { Maximum } \\
\text { Force (N) }\end{array}$ & $\begin{array}{c}\text { AUC } \\
(\mathbf{N} \times \mathbf{m m})\end{array}$ \\
\hline & at $10^{\circ} \mathrm{C}$ & at $10^{\circ} \mathrm{C}$ & at $20^{\circ} \mathrm{C}$ & at $20^{\circ} \mathrm{C}$ \\
\hline 100:0 & $229(18) \mathrm{Aa}$ & $408(14) \mathrm{Aa}$ & $137(1.4) \mathrm{Ab}$ & $302(15) \mathrm{Ab}$ \\
\hline $50: 50$ & $73.5(8.5) \mathrm{Ba}$ & $256(36) \mathrm{Ba}$ & $29.2(0.89)^{\mathrm{Bb}}$ & $145(2.4)^{\mathrm{Bb}}$ \\
\hline $40: 60$ & $64.1(0.96) \mathrm{Ba}$ & $248(16) \mathrm{Ba}$ & $20.9(2.4) \mathrm{Cb}$ & $80.9(13) \mathrm{Cb}$ \\
\hline $30: 70$ & $56.1(0.46)^{\mathrm{Ba}}$ & $217(9.5)^{\mathrm{Ba}}$ & $16.3(0.39) \mathrm{Db}$ & $72.8(4.7) \mathrm{Cb}$ \\
\hline $20: 80$ & $22.1(1.6)^{\mathrm{Ca}}$ & $83.0(5.4) \mathrm{Ca}$ & $5.01(0.29) \mathrm{Eb}$ & 17.8 (1.2) Db \\
\hline $0: 100$ & $1.38(0.016) \mathrm{Cb}$ & $4.47(0.095) \mathrm{Db}$ & $3.49(0.24) \mathrm{Ea}$ & $10.6(0.84) \mathrm{Da}$ \\
\hline
\end{tabular}

Values are given as mean $(n=6)$; values in parentheses are standard deviations. ${ }^{A-E}$ Effect of CB replacement percentage. For each textural parameter and the same temperature $\left(10\right.$ and $\left.20^{\circ} \mathrm{C}\right)$, mean values without the same letter are significantly different $(p<0.05)$. ${ }^{a}, \mathrm{~b}$ Effect of temperature. For each textural parameter and the same CB replacement percentage $(0,50,60,70,80$ and $100 \%)$, mean values without the same letter are significantly different $(p<0.05)$. AUC: area under the force-distance curve.

In relation to the temperature effect, the presence of $\mathrm{CB}$ in the systems, even at a low percentage $(20 \%)$, led to higher values in maximum force and area under the force-distance curve (AUC) at 10 than at $20^{\circ} \mathrm{C}$, corroborating the results derived from the rheological tests. Additionally, this result also reflects that at $10^{\circ} \mathrm{C}$ cacao fat crystallization is almost complete, which means an increment of the system consistency and a hardening of the structure [24].

Conversely, in the 0:100 system, the maximum force and the AUC were significantly higher at 20 than at $10{ }^{\circ} \mathrm{C}$, which reflects a greater gel-like consistency in the system formulated with the OG alone at a higher temperature. This result is also in consonance with the result obtained from the frequency sweeps at both temperatures (Table 2). The values of these textural parameters in the $0: 100$ system at $20{ }^{\circ} \mathrm{C}$ are similar to the ones provided previously by other authors in an OG developed under similar conditions [18], and these values increased with HPMC concentration. In other oleogels prepared by using the emulsion-templated approach, an increase in system consistency was also observed as the hydrocolloid concentration became higher [11,15].

\subsection{Oil-Binding Capacity (OBC) of CB:OG Systems}

$\mathrm{OBC}$ is an important property in a lipid system, and indicates the system capacity to retain oil in its structure, thus denoting its physical stability. The OBC values in the different CB:OG formulated systems are represented in (Table 5). The results show that either after 2 or $24 \mathrm{~h}$, the effect of the percentage of replacement of CB by the OG has a significant effect in the OBC of the samples, in such way that the values decrease as the quantity of OG present in the CB:OG systems increases. Therefore, after both 2 and $24 \mathrm{~h}$, neither the 100:0 control system, nor the 50:50 system, suffered any oil loss, being their OBC was that of a $100 \%$ and reflecting that in the 50:50 mixed system the oil from the OG remains totally retained and immobilized in the complex mix of structures formed. After $2 \mathrm{~h}$ there were no significant differences in oil loss values among the 40:60, 30:70 and 20:80 mixed systems, as these differences were very small between 0.6 and $1 \%$. After $24 \mathrm{~h}$, oil loss in the 40:60 and 20:80 systems increased significantly, and reached values up to $5.4 \%$ in the system with the greatest OG content.

Finally, although the pure OG system (0:100) had the greatest oil loss at 2 and $24 \mathrm{~h}$ its OBC was still very high, with values of 98.4 and $93.4 \%$ respectively (Table 5). This result shows that when $1 \%$ HPMC is added to the oil-in-water emulsion, it favors the formation of a strong physical network with a very high capacity to retain oil drops. It should be noted that the time ( $2 \mathrm{~h}$ vs. $24 \mathrm{~h}$ ) did not have a significant effect on the 100:0, 50:50 and 30:70 systems.

In oleogels developed with HPMC under similar conditions to the ones employed in this study, Espert et al. [18] obtained an OBC of $92.8 \%$ after $24 \mathrm{~h}$. The authors just cited observed that the OBC decreased significantly to $66.2 \%$ when the HPMC concentration 
decreased in the emulsion from 1 to $0.5 \%$, concluding that a minimum HPMC concentration of $1 \%$ is required to trap the oil in the OG after drying. Also, Meng et al. [14] previously provided similar results in oleogels elaborated with the same cellulose ether. In addition, these authors also observed that as the HPMC concentration in the OG increased, its OBC also increased.

Table 5. Oil-binding capacity (OBC) for the different formulated CB:OG systems.

\begin{tabular}{ccc}
\hline CB:OG & OBC (\%) after $\mathbf{2} \mathbf{h}$ & OBC (\%) after $\mathbf{2 4} \mathbf{h}$ \\
\hline $100: 0$ & $100 \pm 0.000^{\mathrm{Aa}}$ & $100 \pm 0.000^{\mathrm{Aa}}$ \\
$50: 50$ & $100 \pm 0.015^{\mathrm{Aa}}$ & $100 \pm 0.01^{\mathrm{Aa}}$ \\
$40: 60$ & $99.2 \pm 0.35^{\mathrm{A}} \mathrm{Ba}$ & $98.6 \pm 0.20^{\mathrm{Bb}}$ \\
$30: 70$ & $99.4 \pm 0.61^{\mathrm{Ba}}$ & $98.5 \pm 0.78^{\mathrm{Ba}}$ \\
$20: 80$ & $99.0 \pm 0.19^{\mathrm{B}, \mathrm{Ca}}$ & $94.6 \pm 0.35^{\mathrm{Cb}}$ \\
$0: 100$ & $98.4 \pm 0.048^{\mathrm{Ca}}$ & $93.4 \pm 0.28^{\mathrm{Db}}$ \\
\hline
\end{tabular}

Mean value $(n=6) \pm$ standard deviation. A-D Effect of CB replacement percentage. For the same time period ( 2 and $24 \mathrm{~h}$ ), mean values without the same letter are significantly different $(p<0.05)$. ${ }^{\mathrm{a}, \mathrm{b}}$ Effect of time period at room temperature. For the same CB replacement percentage $(0,50,60,70$, 80 and $100 \%)$, mean values without the same letter are significantly different $(p<0.05)$.

\section{Conclusions}

The use of HPMC is an adequate strategy to structure a large amount of healthy liquid oil and develop an OG with an improved lipid profile to be used as CB fat replacer. Also, this OG exhibited distinctive characteristics of a plastic and solid-like fat, which represents an essential aspect for its use as a substitute for $C B$, as well as for other saturated fats. Among the CB:OG formulated systems, the $50 \%$ replacement of $C B$ by the OG is a promising technological option in the formulation of chocolates and derivatives, since it provides a healthier lipid profile and physical characteristics similar to genuine $C B$, as its elevated oil retention capacity, rheological, and textural properties reveal. More structural research and sensory evaluation is needed aimed at incorporating the HPMC-based OG obtained by using the emulsion-templated approach into chocolate formulations to validate the main findings of this research.

Supplementary Materials: The following are available online at https://www.mdpi.com/article/10 .3390 /foods10040793/s1, Table S1: Viscoelastic properties derived from temperature sweeps carried out between 20 and $10^{\circ} \mathrm{C}$ for the different CB:OG systems formulated.

Author Contributions: Conceptualization, M.D.A., A.S. and T.S.; methodology, M.D.A., S.C. and M.E.; formal analysis, M.D.A. and S.C.; investigation, M.D.A. and S.C.; resources, M.E.; writingoriginal draft preparation, M.D.A. and S.C.; writing-review and editing, M.E., A.S. and T.S.; visualization, S.C. and M.E.; supervision, A.S. and T.S.; project administration, A.S. and T.S.; funding acquisition, A.S. and T.S. All authors have read and agreed to the published version of the manuscript.

Funding: This research was funded by project RTI-2018-099738-B-C21 from the Spanish Ministry of Economy, Industry and Competitiveness, and Intramural project CSIC: 202070E177.

Institutional Review Board Statement: Not applicable.

Informed Consent Statement: Not applicable.

Data Availability Statement: Data is contained within the article or Supplementary Materials.

Acknowledgments: The authors are grateful to the Analysis Service Unit facilities of ICTAN for the analysis of Chromatography and Mass Flame Ionization.

Conflicts of Interest: The authors declare they do not have any conflict of interest.

\section{References}

1. Demirkesen, I.; Mert, B. Recent Developments of Oleogel Utilizations in Bakery Products. Crit. Rev. Food Sci. Nutr. 2020, 60, 2460-2479. [CrossRef] 
2. Pehlivanoğlu, H.; Demirci, M.; Toker, O.S.; Konar, N.; Karasu, S.; Sagdic, O. Oleogels, A Promising Structured Oil for Decreasing Saturated Fatty Acid Concentrations: Production and Food-Based Applications. Crit. Rev. Food Sci. Nutr. 2018, 58, 1330-1341. [CrossRef]

3. Tavernier, I.; Doan, C.D.; Van der Meeren, P.; Heyman, B.; Dewettinck, K. The Potential of Waxes to Alter the Microstructural Properties of Emulsion-Templated Oleogels. Eur. J. Lipid Sci. Technol. 2018, 120, 170039. [CrossRef]

4. WHO. Diet Nutrition and the Prevention of Chronic Diseases; Technical Report Series 916; World Health Organization: Geneva, Switzerland, 2003.

5. Espert, M.; Bresciani, A.; Salvador, A.; Sanz, T. Functionality of Low Digestibility Emulsions in Cocoa Creams. Structural Changes During in vitro Digestion and Sensory Perception. J. Funct. Foods 2019, 54, 146-153. [CrossRef]

6. $\quad$ Espert, M.; Wiking, L.; Salvador, A.; Sanz, T. Reduced-Fat Spreads Based on Anhydrous Milk Fat and Cellulose Ethers. Food Hydrocoll. 2020, 99, 105330. [CrossRef]

7. Marangoni, A.G.; Narine, S.S. Identifying Key Structural Indicators of Mechanical Strength in Networks of Fat Crystals. Food Res. Int. 2002, 35, 957-969. [CrossRef]

8. Espert, M.; Salvador, A.; Sanz, T.; Hernandez, M.J. Cellulose Ether Emulsions as Fat Source in Cocoa Creams: Thermorheological Properties (Flow and Viscoelasticity). LWT Food Sci. Technol. 2020, 117, 108640. [CrossRef]

9. Gomez-Estaca, J.; Herrero, A.M.; Herranz, B.; Alvarez, M.D.; Jimenez-Colmenero, F.; Cofrades, S. Characterization of Ethyl Cellulose and Beeswax Oleogels and Their Suitability as Fat Replacers in Healthier Lipid Pâtés Development. Food Hydrocoll. 2019, 87, 960-969. [CrossRef]

10. Co, E.D.; Marangoni, A.G. Organogels: An Alternative Edible Oil-Structuring Method. J. Am. Oil Chem. Soc. 2012, 89, 749-780.

11. Patel, A.R.; Rajarethinem, P.S.; Cludts, N.; Lewille, B.; De Vos, W.H.; Lesaffer, A.; Dewettinck, K. Biopolymer-Based Structuring of Liquid Oil Into Soft Solids and Oleogels Using Water-Continuous Emulsions as Templates. Langmuir 2015, 31, $2065-2073$. [CrossRef]

12. Jimenez-Colmenero, F.; Salcedo-Sandoval, L.; Bou, R.; Cofrades, S.; Herrero, A.M.; Ruiz-Capillas, C. Novel Applications of Oil-Structuring Methods as a Strategy to Improve the Fat Content of Meat Products. Trends Food Sci. Technol. 2015, 44, 177-188. [CrossRef]

13. Meng, Z.; Qi, K.Y.; Guo, Y.; Wang, Y.; Liu, Y.F. Effects of Thickening Agents on the Formation and Properties of Edible Oleogels Based on Hydroxypropyl Methyl Cellulose. Food Chem. 2018, 246, 137-149. [CrossRef]

14. Meng, Z.; Qi, K.Y.; Guo, Y.; Wang, Y.; Liu, Y.F. Macro-Micro Structure Characterization and Molecular Properties of EmulsionTemplated Polysaccharide Oleogels. Food Hydrocoll. 2018, 77, 17-29. [CrossRef]

15. Meng, Z.; Qi, K.Y.; Guo, Y.; Wang, Y.; Liu, Y.F. Physical Properties, Microstructure, Intermolecular Forces, and Oxidation Stability of Soybean Oil Oleogels Structured by Different Cellulose Ethers. Eur. J. Lipid Sci. Technol. 2018, 120, 1700287. [CrossRef]

16. Patel, A.R.; Cludts, N.; Bin Sintang, M.D.; Lewille, A.; Lesaffer, K.D. Polysaccharide-Based Oleogels Prepared with an EmulsionTemplated Approach. ChemPhysChem 2014, 15, 3435-3439. [CrossRef]

17. Patel, A.R.; Cludts, N.; Bin Sintang, M.D.; Lesaffer, A.; Dewettinck, K. Edible Oleogels Based on Water Soluble Food Polymers: Preparation, Characterization and Potential Application. Food Funct. 2014, 5, 2833-2841. [CrossRef]

18. Espert, M.; Salvador, A.; Sanz, T. Cellulose Ether Oleogels Obtained by Emulsion-Templated Approach without Additional Thickeners. Food Hydrocoll. 2020, 109, 106085. [CrossRef]

19. Guo, Y.; Cai, Z.; Xie, Y.; Ma, A.; Zhang, H.; Rao, P.; Wang, Q. Synthesis, Physicochemical Properties, and Health Aspects of Structured Lipids: A. Review. Compr. Rev. Food Sci. Food Saf. 2020, 19, 759-800. [CrossRef]

20. Patel, A.R. Structuring Edible Oils with Hydrocolloids: Where do we Stand? Food Biophys. 2018, 13, 113-115. [CrossRef]

21. Jiang, Y.; Liu, L.L.; Wang, B.J.; Sui, X.F.; Zhong, Y.; Zhang, L.P.; Mao, Z.; Xu, H. Cellulose-Rich Oleogels Prepared with an Emulsion-Templated Approach. Food Hydrocoll. 2018, 77, 460-464. [CrossRef]

22. Pizones Ruiz-Henestrosa, V.M.; Bellesi, F.A.; Camino, N.A.; Pilosof, A.M.R. The Impact of HPMC Structure in the Modulation of in Vitro Lipolysis: The Role of Bile Salts. Food Hydrocoll. 2017, 62, 251-261. [CrossRef]

23. Espert, M.; Borriani, J.; Hernando, I.; Quiles, A.; Salvador, A.; Sanz, T. Relationship Between Cellulose Chemical Substitution, Structure and Fat Digestion in o/w Emulsions. Food Hydrocoll. 2017, 69, 76-85. [CrossRef]

24. Bahari, A.; Akoh, C.C. Synthesis of a Cocoa Butter Equivalent by Enzymatic Interesterification of Illipe Butter and Palm Midfraction. J. Am. Oil Chem. Soc. 2018, 95, 547-555. [CrossRef]

25. Kadivar, S.; De Clercq, N.; Danthine, S.; Dewettinck, K. Crystallization and Morphic Behavior of Enzymatically Produced Sunflower Oil Based Cocoa Butter Equivalents. Eur. J. Lipid Sci. Technol. 2016, 118, 1521-1538. [CrossRef]

26. Biswas, N.; Cheow, Y.L.; Tan, C.P.; Kanagaratnam, S.; Siow, L.F. Cocoa Butter Substitute (CBS) Produced from Palm MidFraction/Palm Kernel Oil/Palm Stearin for Confectionery Fillings. J. Am. Oil Chem. Soc. 2017, 94, 235-245. [CrossRef]

27. Undurraga, D.; Markovits, A.; Erazo, S. Cocoa Butter Equivalent Through Enzymic Interesterification of Palm Oil Midfraction. Process. Biochem. 2001, 36, 933-939. [CrossRef]

28. Bahari, A.; Akoh, C.C. Texture, Rheology and Fat Bloom Study of 'Chocolates' Made from Cocoa Butter Equivalent Synthesized from Illipe Butter and Palm Mid-Fraction. LWT Food Sci. Technol. 2018, 97, 349-354. [CrossRef]

29. Kim, B.H.; Akoh, C.C. Recent Research Trends on the Enzymatic Synthesis of Structured Lipids. J. Food Sci. 2015, 80, C1713-C1724. [CrossRef]

30. Ulbricht, T.L.; Southgate, D.A. Coronary Heart Disease: Seven Dietary Factors. Lancet 1991, 338, 985-992. [CrossRef] 
31. Huang, H.; Hallinan, R.; Maleky, F. Comparison of Different Oleogels in Processed Cheese Products Formulation. Int. J. Food Sci. Technol. 2018, 53, 2525-2534. [CrossRef]

32. Jahurul, M.H.A.; Zaidul, I.S.M.; Norulaini, N.A.N.; Sahena, F.; Jinap, S.; Azmir, J.; Sharif, K.M.; Mohd Omar, A.K. Cocoa Butter Fats and Possibilities of Substitution in Food Products Concerning Cocoa Varieties, Alternative Sources, Extraction Methods, Composition, and Characteristics. J. Food Eng. 2013, 117, 467-476. [CrossRef]

33. Kris-Etherton, P.M.; Yu, S. Individual Fatty Acid Effects on Plasma Lipids and Lipoproteins: Human Studies. Am. J. Clin. Nutr. 1997, 65, 1628S-1644S. [CrossRef]

34. Estruch, R.; Ros, E.; Salas-Salvadó, J.; Covas, M.-I.; Corella, D.; Arós, F.; Gómez-Gracia, E.; Ruiz-Gutiérrez, V.; Fiol, M.; Lapetra, J.; et al. Primary Prevention of Cardiovascular Disease with a Mediterranean Diet. N. Engl. J. Med. 2013, 368, 1279-1290. [CrossRef] [PubMed]

35. Bonanome, A.; Grundy, S.M. Effect of Dietary Stearic Acid on Plasma Cholesterol and Lipoprotein Levels. N. Engl. J. Med. 1988, 318, 1244-1248. [CrossRef]

36. Kelly, F.; Sinclair, A.; Mann, N.; Turner, A.; Abedin, L.; Li, D. A Stearic Acid-Rich Diet Improves Thrombogenic and Atherogenic Risk Factor Profiles in Healthy Males. Eur. J. Clin. Nutr. 2001, 55, 88-96. [CrossRef] [PubMed]

37. McAfee, A.J.; McSorley, E.M.; Cuskelly, G.J.; Moss, B.W.; Wallace, J.M.W.; Bonham, M.P.; Fearon, A.M. Red Meat Consumption: An Overview of the Risks and Benefits. Meat Sci. 2010, 84, 1-13. [CrossRef]

38. Wood, J.D.; Richardson, R.I.; Nute, G.R.; Fisher, A.V.; Campo, M.M.; Kasapidou, E.; Sheard, P.R.; Enser, M. Effects of Fatty Acids on Meat Quality: A Review. Meat Sci. 2003, 66, 21-32. [CrossRef]

39. Chai, X.; Meng, Z.; Liu, Y. Relationship Between Lipid Composition and Rheological Properties of Colloidal Fat Crystal Networks: A Comparative Study Using Chemometrics. LWT Food Sci. Technol. 2020, 118, 108814. [CrossRef]

40. Herranz, H.; Tovar, C.A.; Solo-de-Zaldívar, B.; Borderias, J. Effect of Alkalis on Konjac Glucomannan Gels for Use as Potential Gelling Agents in Restructured Seafood Products. Food Hydrocoll. 2012, 27, 145-153. [CrossRef]

41. Nishinari, K. Some Thoughts on the Definition of a Gel. Prog. Colloid Polym. Sci. 2009, 136, 87-94.

42. McGill, J.; Hartel, R.W. Investigation into the Microstructure, Texture and Rheological Properties of Chocolate Ganache. J. Food Sci. 2018, 83, 689-699. [CrossRef] [PubMed]

43. Mendenhall, H.; Hartel, R.W. Effects of Fat Content and Solid Fat Content on Caramel Texture Attributes. J. Am. Oil Chem. Soc. 2016, 93, 1191-1199. [CrossRef] 